\title{
Evaluation of the Diagnostic Efficacy of Xpert CT/NG for Chlamydia trachomatis and Neisseria gonorrhoeae
}

\author{
Tian-Ao Xie, ${ }^{1,2}$ Ye-Ling Liu,, ${ }^{1,2}$ Rui-Chun Meng, ${ }^{1,2}$ Xiao-Shan Liu,, ${ }^{1,2}$ Ke-Ying Fang, ${ }^{1,2}$ \\ Shu-Ting Deng, ${ }^{1,2}$ Shu-Jin Fan, ${ }^{1,2}$ Chu-Mao Chen, ${ }^{2}$ Qin-Rong Lin, ${ }^{1,2}$ Zhi-Jian He, ${ }^{1,2}$ \\ Zhen-Xing Li, ${ }^{3}$ Shi Ouyang, ${ }^{4}$ Guo-Dong Zhu, ${ }^{5}$ Tian-Xing Ji, ${ }^{6}$ Yong Xia, ${ }^{1,2,7,8}$ Zhi-Yong Pan, ${ }^{1,2}$ \\ and Xu-Guang Guo $\mathbb{D}^{1,2,7,8}$ \\ ${ }^{1}$ Department of Clinical Medicine, The Third Clinical School of Guangzhou Medical University, Guangzhou 511436, China \\ ${ }^{2}$ Department of Clinical Laboratory Medicine, The Third Affiliated Hospital of Guangzhou Medical University, \\ Guangzhou 510150, China \\ ${ }^{3}$ Department of Respiratory Medicine, The Third Affiliated Hospital of Guangzhou Medical University, Guangzhou 510150, China \\ ${ }^{4}$ Department of Infectious Disease, The Fifth Affiliated Hospital of Guangzhou Medical University, 510000, China \\ ${ }^{5}$ The Second Affiliated Hospital of South China University of Technology, Geriatrics Related Fundamental and Clinical Research, \\ 510180, China \\ ${ }^{6}$ Department of Clinical Medicine, The Second Affiliated Hospital of Guangzhou Medical University, 511436, China \\ ${ }^{7}$ Key Laboratory for Major Obstetric Diseases of Guangdong Province, The Third Affiliated Hospital of Guangzhou \\ Medical University, Guangzhou 510150, China \\ ${ }^{8}$ Key Laboratory of Reproduction and Genetics of Guangdong Higher Education Institutes, The Third Affiliated Hospital of \\ Guangzhou Medical University, Guangzhou 510150, China
}

Correspondence should be addressed to Xu-Guang Guo; gysygxg@gmail.com

Received 16 June 2020; Accepted 25 August 2020; Published 12 October 2020

Academic Editor: Anjali Joshi

Copyright (C) 2020 Tian-Ao Xie et al. This is an open access article distributed under the Creative Commons Attribution License, which permits unrestricted use, distribution, and reproduction in any medium, provided the original work is properly cited.

Background. Chlamydia trachomatis (CT) and Neisseria gonorrhoeae (NG) are widely spread across the world. Asymptomatic or inconspicuous CT/NG infections are difficult to diagnose and treat. Traditional methods have the disadvantages of low detection rate, inaccurate results, and long detection time. However, Xpert CT/NG makes up for the aforementioned shortcomings and has research value and popularization significance. Methods. PubMed, Embase, Cochrane Library, and Web of Science were systematically searched, and studies were screened using Xpert CT/NG for diagnosing CT/NG. QUADAS-2 was used to evaluate the quality of the eligible studies. Then, two groups of researchers independently extracted data from these studies. Metaanalyses of sensitivity (SEN), specificity (SPE), positive likelihood ratio (PLR), negative likelihood ratio (NLR), diagnostic odds ratio (DOR), and the area under the curve (AUC) of the summary receiver operating characteristic (SROC) curve were conducted using Meta-DiSc 1.4. Finally, Deek's funnel plots were made using Stata 12.0 to evaluate publication bias. Results. 14 studies were identified, and 46 fourfold tables were extracted in this meta-analysis. The pooled SEN, SPE, PLR, NLR, DOR, and AUC in diagnosing CT were 0.94 (95\% confidence interval (CI): 0.93-0.95), 0.99 (95\% CI: 0.99-1.00), 97.17 (95\% CI: $56.76-$ 166.32), 0.07 (95\% CI: 0.04-0.12), 1857.25 (95\% CI: 943.78-3654.86), and 0.9960, respectively. The pooled SEN, SPE, PLR, NLR, DOR, and AUC in diagnosing NG were 0.95 (95\% CI: 0.93-0.96), 1.00 (95\% CI: 1.00-1.00), 278.15 (95\% CI: 152.41-507.63), 0.08 (95\% CI: 0.06-0.12), 4290.70 (95\% CI: 2161.78-8516.16), and 0.9980, respectively. Conclusions. Xpert CT/NG had high diagnostic sensitivity and specificity for CT and NG. However, more evidence is required to confirm that Xpert CT/NG might serve as the primary method for detecting CT and NG and even the gold standard for diagnosis in the future. 


\section{Background}

Chlamydia trachomatis (CT) and Neisseria gonorrhoeae (NG) are the most common infectious bacteria in sexually transmitted infections (STIs) [1]. According to incomplete statistics, CT and NG are widely spread across the world (about 131 million and 78 million, respectively) [2]. Their rate of infection has also increased every year, with a larger fraction in women [3].

CT, a prokaryotic microorganism, is divided into 19 serotypes. In these serotypes, serotypes $\mathrm{A}$ to $\mathrm{C}$ mainly cause trachoma, serotypes $\mathrm{D}$ to $\mathrm{K}$ cause urogenital tract infection, and serotypes L1 to L3 cause lymphogranuloma venereum [4]. The elementary body of CT is one of the two bacterial morphologies that cannot split but is extremely infected. It can differentiate into reticulate bodies (RBs) around the epithelial cells. RBs infect other cells after replication by two divisions, facilitating the spread of CT [5]. Quite a few people infected with CT are asymptomatic or inconspicuous, especially those with genital tract infection [6]. The failure to seek timely medical care can lead to serious complications, such as male urethritis, epididymitis, female cervicitis, and pelvic inflammatory disease $[1,2]$. Children have trachoma more commonly, while newborns acquire CT infection through the genital tracts of their mothers and suffer neonatal ophthalmia and pneumonia [4]. Therefore, the differential diagnosis of CT infection needs immediate attention.

Humans are the natural host of NG [7]. More than one million STIs are acquired every day worldwide $[8,9]$, and NG mainly causes gonorrhea. When NG intrudes tissues of the body, it uses its pili and outer membrane proteins to adhere to mucosal epithelial cells, leading to invasion with endocytosis. Subsequently, NG reproduces fast in host cells causing cell lysis and then enters the submucosa to produce toxins leading to inflammatory reactions [10]. Hence, the body produces purulent secretions representatively. Moreover, up to $50 \%$ to $80 \%$ of women and about $10 \%$ of men have asymptomatic infections [11]. Antibiotics are frequently prescribed to treat gonorrhea. With this widespread use, NG becomes resistant to antibiotics, including extendedspectrum cephalosporin ceftriaxone, affecting the treatment and prognosis of gonococcal infection [12]. In the meantime, NG develops a mechanism to escape from the human immune system [13]. This leads to a dramatic increase in difficulty of treating NG infection.

CT/NG infections can be diagnosed by the antigen-antibody test, serological examination, and nucleic acid amplification tests (NAATs). The indirect methods of detection depend on antibodies with a low detection rate of pathogens. The serological examination is not suitable for acute response in that it usually takes weeks to months with the low accuracy of test results [14]. The use of NAATs is the preferred diagnostic method with high specificity and sensitivity at present, but it still takes several days to detect bacteria [15].

The GeneXpert (Cepheid, USA) is an automatic molecular diagnosis method based on the nucleic acid amplification test [16]. The core of detection technology is the application of $90 \mathrm{~min}$ real-time fluorescent quantitative polymerase chain reaction (FQ-PCR), which has the same performance as traditional NAAT [1]. The Xpert platform integrates and automates sample preparation, nucleic acid purification, gene amplification, and result reporting in quantitative PCR molecular detection [17]. CT and NG pathogens can be detected rapidly on the same day at the same time. The advantages of the Xpert system include the ability to use each machine module independently, allowing the simultaneous screening of multiple samples. It is faster, simpler, more accurate, and safer than the traditional methods [18].

The Xpert CT/NG kit is one type of Xpert platform [16]. Its samples mainly come from the female cervical endometrial swab, vaginal swab, and female or male urine. Subsequently, DNA of CT and NG can be detected using the kit-based assay [16, 19]. Currently, no meta-analysis has investigated the diagnostic accuracy of GeneXpert for CT and NG in the field of evidence-based medicine. This meta-analysis is aimed at exploring the sensitivity and specificity of Cepheid Xpert CT/NG in the diagnosis of $\mathrm{CT}$ and NG infections.

\section{Methods}

2.1. Study Design. This study was conducted from March 2019 to date. The sensitivity and specificity of Xpert CT/NG in identifying CT and NG were systematically evaluated.

2.2. Electronic Searches. PubMed, Embase, the Cochrane Library, and Web of Science were systematically searched using the following terms: (Xpert CT/NG OR Xpert OR GeneXpert OR Xpert CT OR Xpert NG OR Cepheid) AND (Chlamydia trachomatis [all synonyms] OR Neisseria gonorrhoeae [all synonyms]) (last search: 5 March 2020). There are language restrictions: we only include English literature. Relevant studies from January 2000 to March 2020 from the aforementioned four databases were included.

2.3. Inclusion and Exclusion Criteria. The studies were searched from the database, and the details were imported into EndNote X8. The four members of the research team were divided into two groups (TA Xie and RC Meng; YL Liu and XS Liu). Each group was responsible for half of the studies. Duplicate documents were independently examined and deleted. Also, the literature abstracts were reviewed, and the full text was read carefully. In the case of a problem that could not be solved within the group, another person was selected as a third party to negotiate and solve it. The inclusion and exclusion criteria were established for suitability of studies, and all search results were evaluated. The inclusion criteria were as follows: (1) the research type must study the clinical application effect of Xpert CT/NG kit, (2) the target should be the carrier of CT/NG, (3) the diagnostic method should use the Xpert CT/NG kit, and (4) the measurement index should also be the content of CT/NG. The exclusion criteria were as follows: (1) the conference abstract was excluded because quality evaluation could not be conducted, (2) studies in which fourfold tables could not be extracted were excluded, and (3) letters and reviews were excluded because they were incomplete and difficult to meta-analysis. 
TABLE 1: Characteristics about CT from included articles.

\begin{tabular}{|c|c|c|c|c|c|c|c|c|c|c|c|}
\hline \multirow{2}{*}{ Author } & \multirow{2}{*}{ Year } & \multirow{2}{*}{ Country } & \multirow{2}{*}{$\begin{array}{l}\text { Study } \\
\text { design }\end{array}$} & \multirow{2}{*}{$\begin{array}{c}\text { Gold } \\
\text { standard }\end{array}$} & \multirow{2}{*}{ Source of specimens } & \multirow{2}{*}{$\begin{array}{c}\text { Bacterial } \\
\text { species }\end{array}$} & \multirow{2}{*}{$\begin{array}{c}\text { Type of } \\
\text { specimens }\end{array}$} & \multicolumn{4}{|c|}{ Result } \\
\hline & & & & & & & & $\mathrm{TP}$ & FP & FN & $\mathrm{TN}$ \\
\hline \multirow[t]{2}{*}{ Goldenberg } & \multirow[t]{2}{*}{2012} & \multirow[t]{2}{*}{ Britain } & \multirow[t]{2}{*}{ Prospective } & \multirow[t]{2}{*}{ PCR } & 409 self-collected specimen & CT & Anorectal & 37 & 3 & 6 & 363 \\
\hline & & & & & 1710 clinical specimens & CT & Endocervical & 76 & 7 & 2 & 1625 \\
\hline \multirow[t]{2}{*}{ Gaydos } & \multirow[t]{2}{*}{2013} & \multirow[t]{2}{*}{ America } & \multirow[t]{2}{*}{ Prospective } & \multirow[t]{2}{*}{ PCR } & 1718 clinical specimens & & Urine $^{\mathrm{a}}$ & 80 & 3 & 2 & 1633 \\
\hline & & & & & 1386 clinical specimens & & Urine $^{\mathrm{b}}$ & 79 & 1 & 2 & 1304 \\
\hline Jenson & 2013 & $\begin{array}{c}\text { East } \\
\text { Africa }\end{array}$ & Prospective & PCR & $\begin{array}{l}144 \text { specimens from trachoma- } \\
\text { endemic community }\end{array}$ & CT & Ocular & 35 & 5 & 0 & 87 \\
\hline Causer & 2015 & Australia & PCR & PCR & 198 clinical specimens & CT & Urine & 16 & 1 & 0 & 181 \\
\hline Peuchan & 2015 & France & Prospective & PCR & 377 clinical specimens & CT & Vaginal & 37 & 0 & 1 & 339 \\
\hline \multirow{2}{*}{ Geiger } & \multirow{2}{*}{2016} & \multirow{2}{*}{ America } & \multirow{2}{*}{ Prospective } & \multirow{2}{*}{ PCR } & \multirow{2}{*}{285 self-collected specimens } & \multirow[t]{2}{*}{ CT } & Ocular & 1 & 0 & 1 & 142 \\
\hline & & & & & & & Anorectal & 15 & 0 & 2 & 124 \\
\hline Bristow & 2017 & America & Prospective & PCR & 393 clinical specimens & CT & Anorectal & 42 & 2 & 7 & 342 \\
\hline \multirow{4}{*}{ Cosentino } & \multirow{4}{*}{2017} & \multirow{4}{*}{ America } & \multirow{4}{*}{ Prospective } & \multirow{4}{*}{ PCR } & 399 clinical specimens & CT & Anorectal & 51 & 6 & 3 & 339 \\
\hline & & & & & 394 clinical specimens & & Pharyngeal & 8 & 2 & 0 & 384 \\
\hline & & & & & 224 clinical specimens & & Urine $^{\mathrm{b}}$ & 9 & 0 & 1 & 214 \\
\hline & & & & & 170 clinical specimens & & Vaginal & 10 & 0 & 1 & 152 \\
\hline Dize & 2017 & America & Prospective & PCR & 448 self-collected specimens & CT & Anorectal & 21 & 1 & 1 & 378 \\
\hline Wilson & 2017 & America & Procnective & $\mathrm{P} C \mathrm{P}$ & 50 clinical specimens & $\mathrm{CT}$ & Urine $^{\mathrm{b}}$ & 8 & 1 & 2 & 39 \\
\hline villson & 2017 & Amintica & Prospective & PCK & 1112 clinical specimens & & Urine $^{\mathrm{a}}$ & 101 & 8 & 24 & 979 \\
\hline Causer & 2018 & Australia & Prospective & PCR & 2486 self-collected specimens & CT & $\begin{array}{l}\text { Urine, } \\
\text { vaginal }\end{array}$ & 209 & 11 & 3 & 2263 \\
\hline & & & & & & CT & Anorectal $^{\mathrm{c}}$ & 144 & 8 & 5 & 169 \\
\hline Badman & 2018 & Australia & Prospective & PCR & 326 self-collected specimens & & Anorectal $^{\mathrm{d}}$ & 116 & 3 & 4 & 127 \\
\hline & & & & & & & Anorectal $^{\mathrm{e}}$ & 28 & 5 & 1 & 42 \\
\hline Gaydos & 2018 & America & Prospective & PCR & 127 clinical specimens & $\mathrm{CT}$ & Endocervical & 10 & 0 & 0 & 117 \\
\hline Garrett & 2019 & $\begin{array}{l}\text { South } \\
\text { Africa }\end{array}$ & Prospective & PCR & 247 clinical specimens & CT & Vaginal & 37 & 5 & 0 & 205 \\
\hline
\end{tabular}

${ }^{a}$ These specimens were collected from female. ${ }^{\mathrm{b}}$ These specimens were collected from male. ${ }^{\mathrm{c}}$ These specimens were collected from "men who have sex with men," "transgender women," and "female sex workers." "These specimens were collected from "female sex workers." "These specimens were collected from "men who have sex with men" and "transgender women." TP: true positive; FP: false positive; FN: false negative; TN: true negative.

2.4. Data Extraction. According to the previous inclusion and exclusion criteria, conference abstracts, letters, reviews, and studies in which fourfold tables could not be extracted were excluded. The remaining studies that met the inclusion criteria were retained, and the data of the included articles were extracted independently by the two groups. The extracted data included author, year, country, study design, gold standard, source of specimens, bacterial species, type of specimens, and result.

2.5. Assessment of Quality of Studies. After data extraction, the quality of the study included in the meta-analysis was evaluated by referring to the Cochrane collaboration QUADAS-2 standard, in which the responses "Yes," "Unclear," and "No" were used for evaluation [20].

2.6. Data Analysis. Meta-DiSc 1.4 was used to integrate the sensitivity and specificity, fit SROC curve, and provide common likelihood ratio, diagnostic odds ratio (DOR), heterogeneity test, and meta-regression analysis functions for the sensitivity, specificity, positive LR, negative LR, diagnostic OR, and SROC curve map [21]. Then, Deek's funnel plots were made using Stata 12.0 to evaluate publication bias.

\section{Results}

3.1. Search Results. Based on the previous retrieval strategy, 326 relevant studies were obtained, including 76 in PubMed, 153 in Embase, 12 in Cochrane, and 85 in the Web of Science. After deletion of duplicate studies, 185 studies remained. Then, 90 irrelevant studies were excluded after reviewing the abstract. After full-text review, finally, fourteen studies [22-35] were included in the meta-analysis. Among the excluded studies, 81 were excluded because they did not meet the inclusion criteria, including 2 reviews, 3 letters, 1 note, 52 conference abstracts, 1 clinical trial protocol, and 22 articles in which fourfold tables could not be extracted. From the remaining 14 studies, 46 sets of research data were extracted (Supplementary Figure 1). In total, we extracted 13442 specimens from the studies. 
TABLE 2: Characteristics about NG from included articles.

\begin{tabular}{|c|c|c|c|c|c|c|c|c|c|c|c|}
\hline \multirow{2}{*}{ Author } & \multirow{2}{*}{ Year } & \multirow{2}{*}{ Country } & \multirow{2}{*}{$\begin{array}{l}\text { Study } \\
\text { design }\end{array}$} & \multirow{2}{*}{$\begin{array}{c}\text { Gold } \\
\text { standard }\end{array}$} & \multirow{2}{*}{ Source of specimens } & \multirow{2}{*}{$\begin{array}{c}\text { Bacterial } \\
\text { species }\end{array}$} & \multirow{2}{*}{$\begin{array}{c}\text { Type of } \\
\text { specimens }\end{array}$} & \multicolumn{4}{|c|}{ Result } \\
\hline & & & & & & & & $\mathrm{TP}$ & FP & $\mathrm{FN}$ & $\mathrm{TN}$ \\
\hline Goldenberg & 2012 & Britain & Prospective & PCR & $\begin{array}{l}409 \text { self-collected } \\
\text { specimens }\end{array}$ & NG & Anorectal & 51 & 0 & 5 & 353 \\
\hline \multirow{3}{*}{ Gaydos } & \multirow{3}{*}{2013} & \multirow{3}{*}{ America } & \multirow{3}{*}{ Prospective } & \multirow{3}{*}{ PCR } & 1710 clinical specimens & NG & Endocervical & 22 & 0 & 0 & 1688 \\
\hline & & & & & 1718 clinical specimens & & Urine $^{\mathrm{a}}$ & 22 & 1 & 1 & 1694 \\
\hline & & & & & 1386 clinical specimens & & Urine $^{b}$ & 49 & 1 & 1 & 1335 \\
\hline Causer & 2015 & Australia & Prospective & PCR & 198 clinical specimens & NG & Urine & 7 & 0 & 0 & 191 \\
\hline Peuchan & 2015 & France & Prospective & PCR & 377 clinical specimens & NG & Vaginal & 7 & 0 & 0 & 370 \\
\hline \multirow{2}{*}{ Geiger } & \multirow{2}{*}{2016} & \multirow{2}{*}{ America } & \multirow{2}{*}{ Prospective } & \multirow{2}{*}{ PCR } & \multirow{2}{*}{$\begin{array}{l}285 \text { self-collected } \\
\text { specimens }\end{array}$} & \multirow[t]{2}{*}{ NG } & Ocular & 7 & 0 & 2 & 135 \\
\hline & & & & & & & Anorectal & 4 & 0 & 0 & 137 \\
\hline \multirow{2}{*}{ Bristow } & \multirow{2}{*}{2017} & \multirow{2}{*}{ America } & \multirow{2}{*}{ Prospective } & \multirow{2}{*}{ PCR } & 391 clinical specimens & NG & Anorectal & 38 & 2 & 5 & 346 \\
\hline & & & & & 448 clinical specimens & & Pharyngeal & 31 & 4 & 3 & 410 \\
\hline \multirow{4}{*}{ Cosentino } & \multirow{4}{*}{2017} & \multirow{4}{*}{ America } & \multirow{4}{*}{ Prospective } & \multirow{4}{*}{ PCR } & 399 clinical specimens & NG & Anorectal & 28 & 2 & 0 & 369 \\
\hline & & & & & 394 clinical specimens & & Pharyngeal & 36 & 9 & 1 & 348 \\
\hline & & & & & 224 clinical specimens & & Urine $^{\mathrm{b}}$ & 12 & 0 & 0 & 212 \\
\hline & & & & & 170 clinical specimens & & Vaginal & 4 & 0 & 1 & 165 \\
\hline Dize & 2017 & America & Prospective & PCR & $\begin{array}{l}448 \text { self-collected } \\
\text { specimens }\end{array}$ & NG & Anorectal & 7 & 0 & 0 & 394 \\
\hline & 2017 & & & PCR & 50 clinical specimens & NG & Urine $^{\mathrm{b}}$ & 4 & 0 & 0 & 46 \\
\hline Wilson & 2017 & America & Prospective & PCK & 1112 clinical specimens & & Urine $^{\mathrm{a}}$ & 41 & 5 & 7 & 1059 \\
\hline Causer & 2018 & Australia & Prospective & PCR & $\begin{array}{l}2486 \text { self-collected } \\
\text { specimens }\end{array}$ & NG & Urine, vaginal & 145 & 2 & 0 & 2339 \\
\hline & & & & & & NG & Anorectal $^{\mathrm{C}}$ & 93 & 0 & 7 & 226 \\
\hline Badman & 2018 & Australia & Prospective & PCR & $\begin{array}{l}326 \text { self-collected } \\
\text { specimens }\end{array}$ & & Anorectal $^{\mathrm{d}}$ & 72 & 0 & 6 & 172 \\
\hline & & & & & & & Anorectal $^{\mathrm{e}}$ & 22 & 0 & 0 & 54 \\
\hline Gaydos & 2018 & America & Prospective & PCR & 127 clinical specimens & NG & Endocervical & 5 & 0 & 0 & 122 \\
\hline Garrett & 2019 & $\begin{array}{l}\text { South } \\
\text { Africa }\end{array}$ & Prospective & PCR & 247 clinical specimens & NG & Vaginal & 12 & 0 & 0 & 235 \\
\hline
\end{tabular}

aThese specimens were collected from female. ${ }^{\mathrm{b}}$ These specimens were collected from male. "These specimens were collected from "men who have sex with men," "transgender women," and "female sex workers." dThese specimens were collected from "female sex workers." "These specimens were collected from "men who have sex with men" and "transgender women." TP: true positive; FP: false positive; FN: false negative; TN: true negative.

3.2. Characteristics of Studies. Information on author, year, country, study design, gold standard, source of specimens, bacterial species, type of specimens, and result was extracted from the included eight studies. The characteristics of the studies on CT are summarized in Table 1. The characteristics of the studies on NG are summarized in Table 2.

3.3. Quality Assessment. The quality of these eight studies was evaluated using the QUADAS-2. In the process of evaluation, "Yes," "Unclear," and "No" responses were used to assess the studies. The specific quality assessment results are shown in Table 3.

3.4. Merge Analysis Results. Meta-DiSc 1.4 software was used to analyze the fourfold table data extracted from these eight studies.

The results on CT are shown in Figures 1-5. Xpert CT/NG was used to detect CT merger sensitivity, specificity, positive LR, negative LR, and diagnostic OR; the values were 0.94 (95\% CI: 0.93-0.95), 0.99 (95\% CI: 0.99-1.00), 97.17
(95\% CI: 56.76-166.32), 0.07 (95\% CI: 0.04-0.12), and 1857.25 (95\% CI: 943.78-3654.86), respectively.

The results on NG are shown in Figures 6-10. Xpert CT/NG was used to detect CT merger sensitivity, specificity, positive LR, negative LR, and diagnostic OR; the values were 0.95 (95\% CI: 0.93-0.96), 1.00 (95\% CI: 1.00-1.00), 278.15 (95\% CI: 152.41-507.63), 0.08 (95\% CI: 0.06- 0.12), and 4290.70 (95\% CI: 2161.78-8516.16), respectively.

3.5. SROC Curve. The SROC curve on CT is shown in Figure 11 ( $\mathrm{AUC}=0.9960 ; Q$ index 0.9762; $\mathrm{SE}=0.0063$ ). The SROC curve on $\mathrm{NG}$ is shown in Figure 12 $(\mathrm{AUC}=0.9980 ; \mathrm{Q}$ index 0.9847; $\mathrm{SE}=0.0073)$. As the AUC values of both were very close to 1 , it was suggested that Xpert CT/NG had high identification accuracy for CT and NG.

3.6. Subgroup Analysis. Significant heterogeneity was found in these studies because $I$-square values were more than 50\% (Figures 1, 2, 6, and 7).

In the subgroup analysis of specimen type in CT, the pooled sensitivity of anorectal, urine, and vaginal specimens 
TABLE 3: Quality evaluation of the included articles.

\begin{tabular}{|c|c|c|c|c|c|c|c|c|c|c|c|c|}
\hline \multirow{2}{*}{ Author } & \multirow{2}{*}{ Year } & \multicolumn{11}{|c|}{ QUADAS-2 } \\
\hline & & 1 & 2 & 3 & 4 & 5 & 6 & 7 & 8 & 9 & 10 & 11 \\
\hline Goldenberg & 2012 & $\mathrm{Y}$ & $\mathrm{Y}$ & $\mathrm{Y}$ & UC & $\mathrm{UC}$ & $\mathrm{Y}$ & $\mathrm{Y}$ & $\mathrm{Y}$ & $\mathrm{Y}$ & $\mathrm{Y}$ & $\mathrm{Y}$ \\
\hline Gaydos & 2013 & $\mathrm{Y}$ & $\mathrm{Y}$ & UC & $\mathrm{N}$ & UC & $\mathrm{Y}$ & $\mathrm{Y}$ & UC & $\mathrm{Y}$ & $\mathrm{Y}$ & $\mathrm{N}$ \\
\hline Jenson & 2013 & $\mathrm{Y}$ & $\mathrm{Y}$ & $\mathrm{N}$ & $\mathrm{Y}$ & UC & $\mathrm{Y}$ & $\mathrm{Y}$ & $\mathrm{N}$ & $\mathrm{Y}$ & $\mathrm{Y}$ & $\mathrm{Y}$ \\
\hline Causer & 2015 & $\mathrm{Y}$ & $\mathrm{Y}$ & $\mathrm{Y}$ & $\mathrm{Y}$ & UC & $\mathrm{Y}$ & $\mathrm{UC}$ & $\mathrm{Y}$ & $\mathrm{Y}$ & $\mathrm{Y}$ & $\mathrm{Y}$ \\
\hline Peuchant & 2015 & $\mathrm{Y}$ & $\mathrm{Y}$ & $\mathrm{Y}$ & $\mathrm{Y}$ & UC & $\mathrm{Y}$ & $\mathrm{N}$ & $\mathrm{Y}$ & $\mathrm{Y}$ & $\mathrm{Y}$ & $\mathrm{Y}$ \\
\hline Geiger & 2016 & $\mathrm{Y}$ & $\mathrm{Y}$ & $\mathrm{Y}$ & $\mathrm{Y}$ & UC & $\mathrm{Y}$ & $\mathrm{Y}$ & $\mathrm{Y}$ & $\mathrm{Y}$ & $\mathrm{Y}$ & $\mathrm{Y}$ \\
\hline Bristow & 2017 & $\mathrm{Y}$ & $\mathrm{Y}$ & UC & $\mathrm{N}$ & UC & $\mathrm{Y}$ & $\mathrm{Y}$ & $\mathrm{Y}$ & $\mathrm{Y}$ & $\mathrm{Y}$ & $\mathrm{Y}$ \\
\hline Cosentino & 2017 & $\mathrm{Y}$ & $\mathrm{N}$ & $\mathrm{N}$ & $\mathrm{Y}$ & UC & $\mathrm{Y}$ & $\mathrm{N}$ & $\mathrm{Y}$ & $\mathrm{N}$ & $\mathrm{N}$ & $\mathrm{Y}$ \\
\hline Dize & 2017 & UC & $\mathrm{Y}$ & $\mathrm{N}$ & $\mathrm{N}$ & UC & $\mathrm{Y}$ & $\mathrm{Y}$ & $\mathrm{Y}$ & $\mathrm{Y}$ & $\mathrm{Y}$ & $\mathrm{Y}$ \\
\hline Wilson & 2017 & $\mathrm{Y}$ & $\mathrm{N}$ & $\mathrm{N}$ & $\mathrm{N}$ & UC & $\mathrm{Y}$ & $\mathrm{Y}$ & $\mathrm{Y}$ & $\mathrm{Y}$ & $\mathrm{Y}$ & $\mathrm{N}$ \\
\hline Causer & 2018 & $\mathrm{Y}$ & $\mathrm{Y}$ & $\mathrm{N}$ & $\mathrm{Y}$ & UC & $\mathrm{Y}$ & $\mathrm{N}$ & $\mathrm{Y}$ & $\mathrm{N}$ & $\mathrm{N}$ & $\mathrm{Y}$ \\
\hline Badman & 2018 & $\mathrm{Y}$ & $\mathrm{Y}$ & $\mathrm{N}$ & $\mathrm{Y}$ & UC & $\mathrm{Y}$ & $\mathrm{N}$ & $\mathrm{Y}$ & $\mathrm{N}$ & $\mathrm{N}$ & $\mathrm{N}$ \\
\hline Gaydos & 2018 & $\mathrm{Y}$ & $\mathrm{Y}$ & $\mathrm{N}$ & UC & UC & $\mathrm{Y}$ & UC & $\mathrm{Y}$ & $\mathrm{Y}$ & $\mathrm{Y}$ & $\mathrm{Y}$ \\
\hline Garrett & 2019 & $\mathrm{Y}$ & $\mathrm{Y}$ & $\mathrm{N}$ & $\mathrm{Y}$ & UC & $\mathrm{Y}$ & $\mathrm{N}$ & $\mathrm{Y}$ & $\mathrm{N}$ & $\mathrm{N}$ & $\mathrm{N}$ \\
\hline
\end{tabular}

1: Was a consecutive or random sample of patients enrolled?; 2: Was a case-control design avoided.; 3: Did the study avoid inappropriate exclusions?; 4: Were the index test results interpreted without knowledge of the results of the reference standard?; 5: If a threshold was used, was it pre-specified?; 6: Is the reference standards likely to correctly classify the target condition?; 7: Were the reference standard results interpreted without knowledge of the results of the index tests?; 8: Was there an appropriate interval between index test and reference standard?; 9: Did all patients receive the reference standard?; 10: Did all patients receive the same reference standard?; 11: Were all patients included in the analysis?

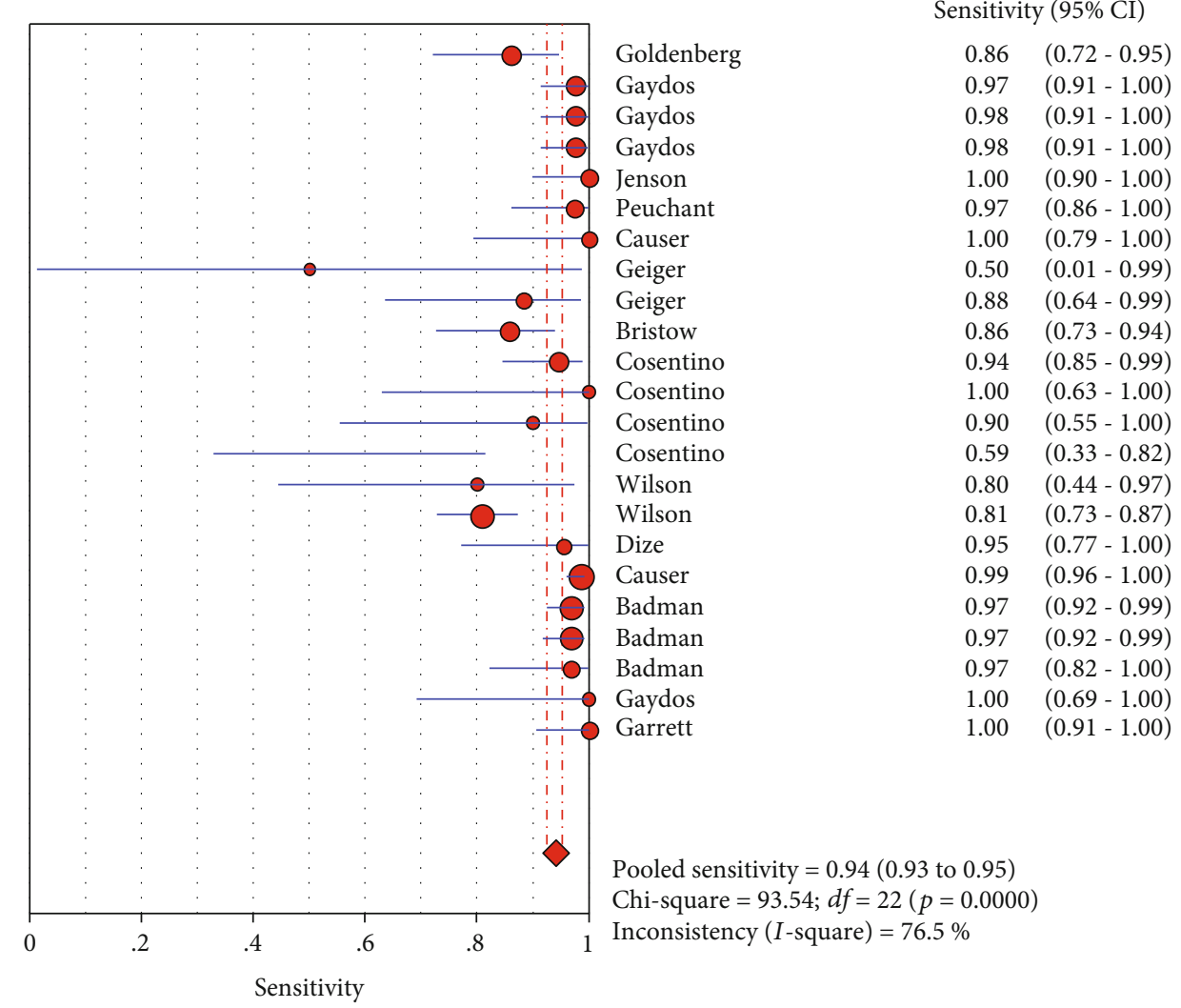

FIGURE 1: Forest plots of the combined sensitivity of Xpert CT/NG for the diagnosis of Chlamydia trachomatis.

was 0.94 (95\% CI: $\left.0.91-0.96 ; I^{2}: 47.1 \%\right), 0.90$ (95\% CI: $0.87-$ $0.93 ; I^{2}: 82.2 \%$ ), and 0.91 (95\% CI: $\left.0.84-0.96 ; I^{2}: 90.9 \%\right)$, respectively. The pooled specificity of anorectal, urine, and vaginal specimens was 0.99 (95\% CI: $\left.0.98-0.99 ; I^{2}: 78.6 \%\right)$, 1.00 (95\% CI: 0.99-1.00; $I^{2}: 63.9 \%$ ), and 0.99 (95\% CI: $\left.0.98-1.00 ; I^{2}: 79.6 \%\right)$, respectively. 


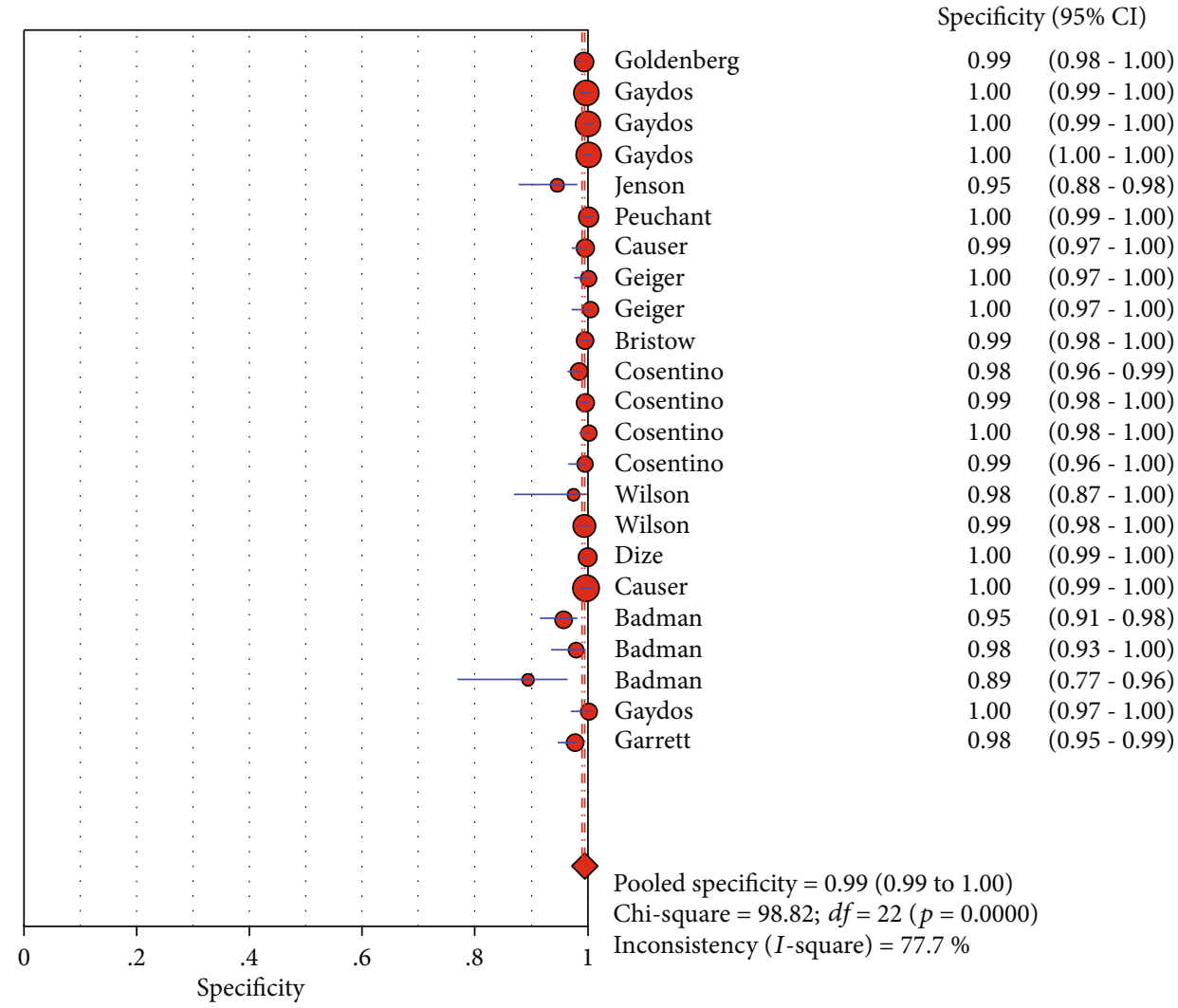

FIGURE 2: Forest plots of the combined specificity of Xpert CT/NG for the diagnosis of Chlamydia trachomatis.

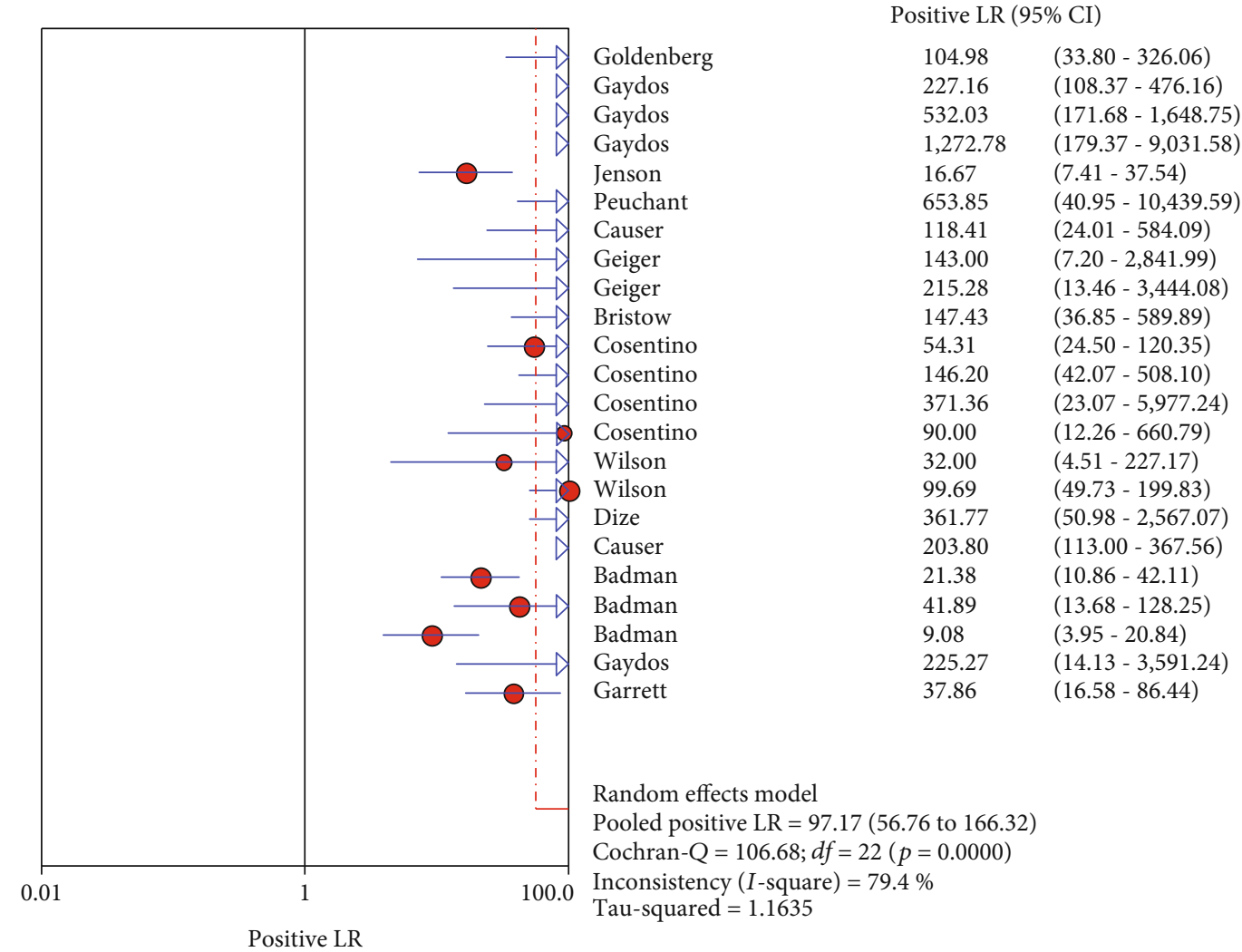

FIGURE 3: Forest plots of the combined positive LR of Xpert CT/NG for the diagnosis of Chlamydia trachomatis. 


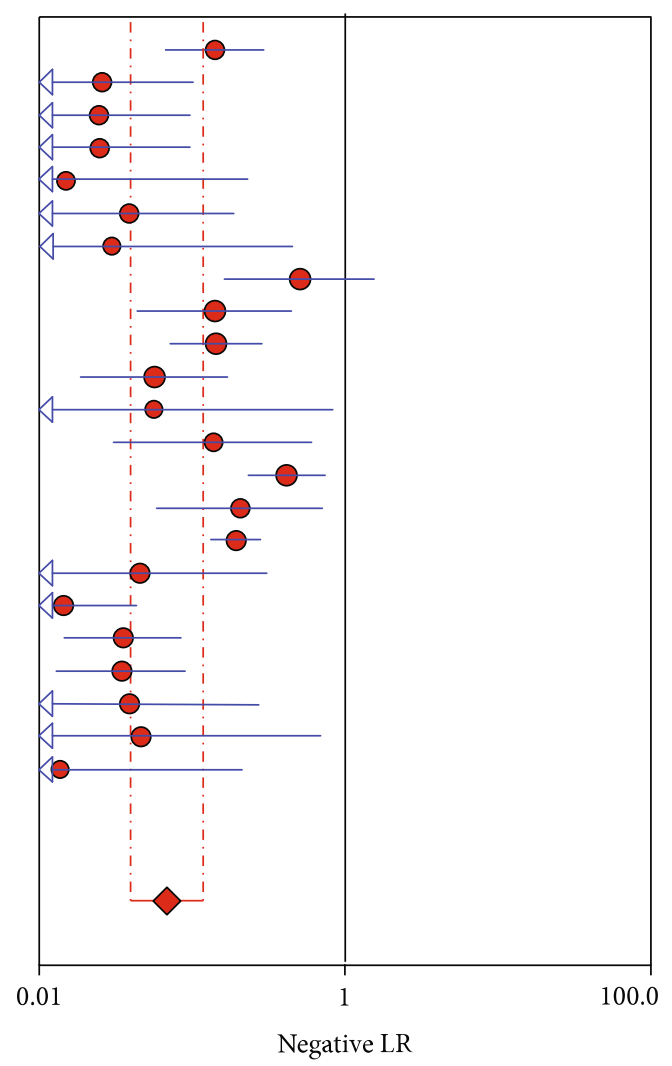

$\begin{array}{lll}\text { Goldenberg } & 0.14 & (0.07-0.30) \\ \text { Gaydos } & 0.03 & (0.01-0.10) \\ \text { Gaydos } & 0.02 & (0.01-0.10) \\ \text { Gaydos } & 0.02 & (0.01-0.10) \\ \text { Jenson } & 0.01 & (0.00-0.23) \\ \text { Peuchant } & 0.04 & (0.01-0.19) \\ \text { Causer } & 0.03 & (0.00-0.46) \\ \text { Geiger } & 0.50 & (0.16-1.56) \\ \text { Geiger } & 0.14 & (0.04-0.44) \\ \text { Bristow } & 0.14 & (0.07-0.29) \\ \text { Cosentino } & 0.06 & (0.02-0.17) \\ \text { Cosentino } & 0.06 & (0.00-0.83) \\ \text { Cosentino } & 0.14 & (0.03-0.60) \\ \text { Cosentino } & 0.41 & (0.23-0.73) \\ \text { Wilson } & 0.21 & (0.06-0.71) \\ \text { Wilson } & 0.19 & (0.14-0.28) \\ \text { Dize } & 0.05 & (0.01-0.31) \\ \text { Causer } & 0.01 & (0.00-0.04) \\ \text { Badman } & 0.04 & (0.01-0.08) \\ \text { Badman } & 0.03 & (0.01-0.09) \\ \text { Badman } & 0.04 & (0.01-0.27) \\ \text { Gaydos } & 0.05 & (0.00-0.68) \\ \text { Garrett } & 0.01 & (0.00-0.21)\end{array}$

Random effects model

Pooled negative $\mathrm{LR}=0.07$ (0.04 to 0.12 )

Cochran- $Q=122.12 ; d f=22(p=0.0000)$

Inconsistency $(I$-square $)=82.0 \%$

Tau-squared $=1.2270$

FIGURE 4: Forest plots of the combined negative LR of Xpert CT/NG for the diagnosis of Chlamydia trachomatis.

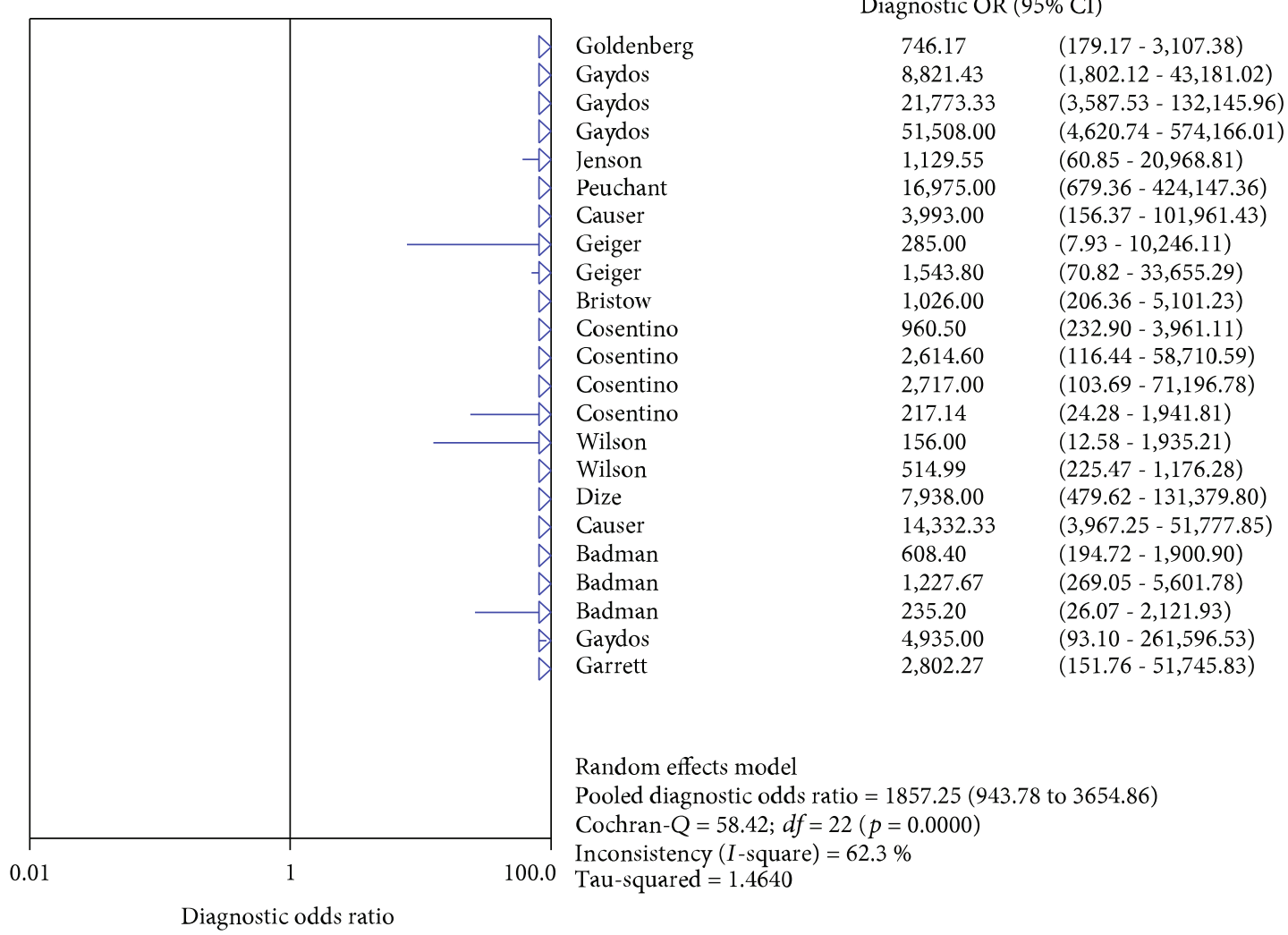

FIgURE 5: Forest plots of the combined diagnostic OR of Xpert CT/NG for the diagnosis of Chlamydia trachomatis. 


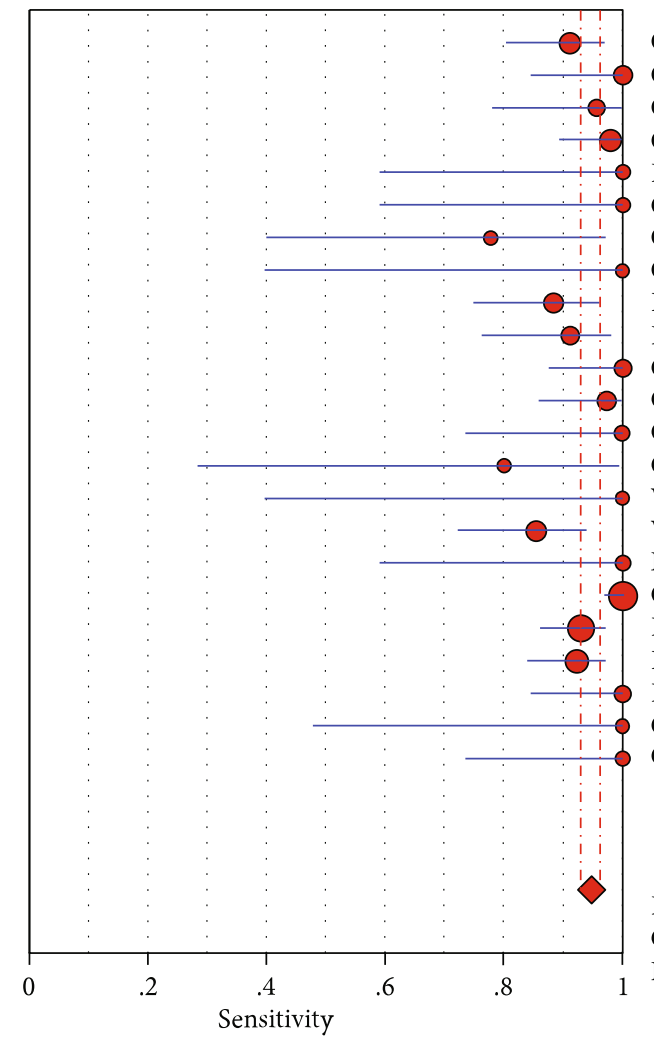

\section{Goldenberg}

Gaydos

Gaydos

Gaydos

Peuchant

Causer

Geiger

Bristow

Bristow

Cosentino

Cosentino

Cosentino

Cosentino

Sensitivity (95\% CI)

$0.91 \quad(0.80-0.97)$

$1.00 \quad(0.85-1.00)$

$0.96 \quad(0.78-1.00)$

$0.98 \quad(0.89-1.00)$

$1.00 \quad(0.59-1.00)$

$1.00 \quad(0.59-1.00)$

$0.78 \quad(0.40-0.97)$

$1.00 \quad(0.40-1.00)$

$0.88 \quad(0.75-0.96)$

$0.91 \quad(0.76-0.98)$

$1.00 \quad(0.88-1.00)$

$0.97 \quad(0.86-1.00)$

$1.00 \quad(0.74-1.00)$

$0.80 \quad(0.28-0.99)$

$1.00 \quad(0.40-1.00)$

$0.85 \quad(0.72-0.94)$

$1.00 \quad(0.59-1.00)$

$1.00 \quad(0.97-1.00)$

$0.93 \quad(0.86-0.97)$

$0.92 \quad(0.84-0.97)$

$1.00 \quad(0.85-1.00)$

$1.00 \quad(0.48-1.00)$

$1.00 \quad(0.74-1.00)$

Pooled sensitivity $=0.95$ (0.93 to 0.96$)$

Chi-square $=47.81 ; d f=22(p=0.0011)$

Inconsistency $(I$-square $)=54.0 \%$

FIgURE 6: Forest plots of the combined sensitivity of Xpert CT/NG for the diagnosis of Neisseria gonorrhoeae.

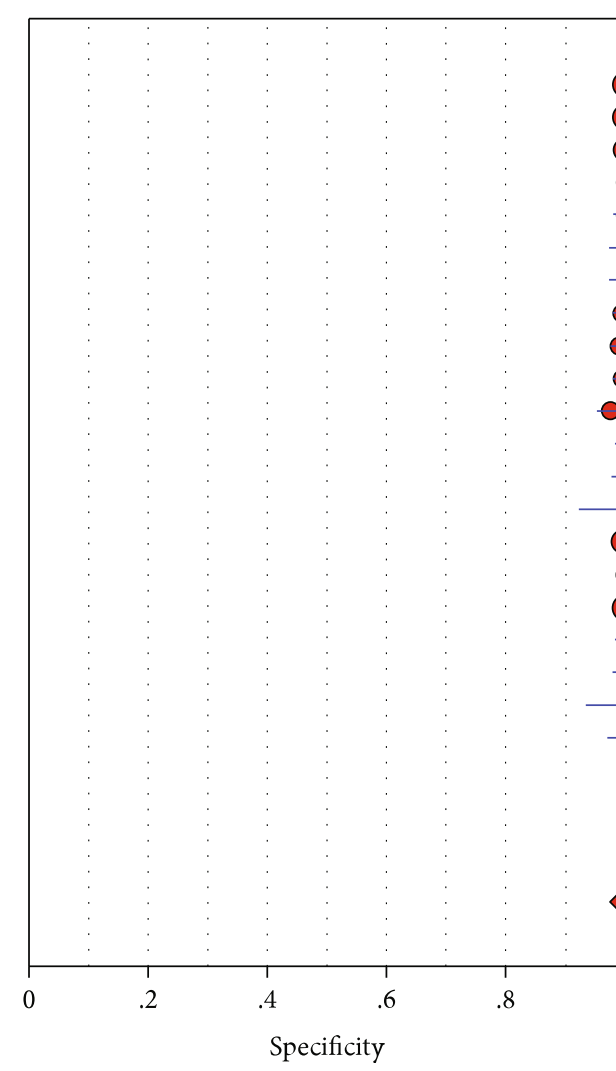

$\begin{array}{cc}\text { Specificity }(95 \% \mathrm{CI}) \\ 1.00 & (0.99-1.00) \\ 1.00 & (1.00-1.00) \\ 1.00 & (1.00-1.00) \\ 1.00 & (1.00-1.00) \\ 1.00 & (0.99-1.00) \\ 1.00 & (0.98-1.00) \\ 1.00 & (0.97-1.00) \\ 1.00 & (0.97-1.00) \\ 0.99 & (0.98-1.00) \\ 0.99 & (0.98-1.00) \\ 0.99 & (0.98-1.00) \\ 0.97 & (0.95-0.99) \\ 1.00 & (0.98-1.00) \\ 1.00 & (0.98-1.00) \\ 1.00 & (0.92-1.00) \\ 1.00 & (0.99-1.00) \\ 1.00 & (0.99-1.00) \\ 1.00 & (1.00-1.00) \\ 1.00 & (0.98-1.00) \\ 1.00 & (0.98-1.00) \\ 1.00 & (0.93-1.00) \\ 1.00 & (0.97-1.00) \\ 1.00 & (0.98-1.00)\end{array}$

Pooled specificity $=1.00(1.00$ to 1.00$)$

Chi-square $=65.05 ; d f=22(p=0.0000)$

Inconsistency $(I$-square $)=66.2 \%$

FIGURE 7: Forest plots of the combined specificity of Xpert CT/NG for the diagnosis of Neisseria gonorrhoeae. 


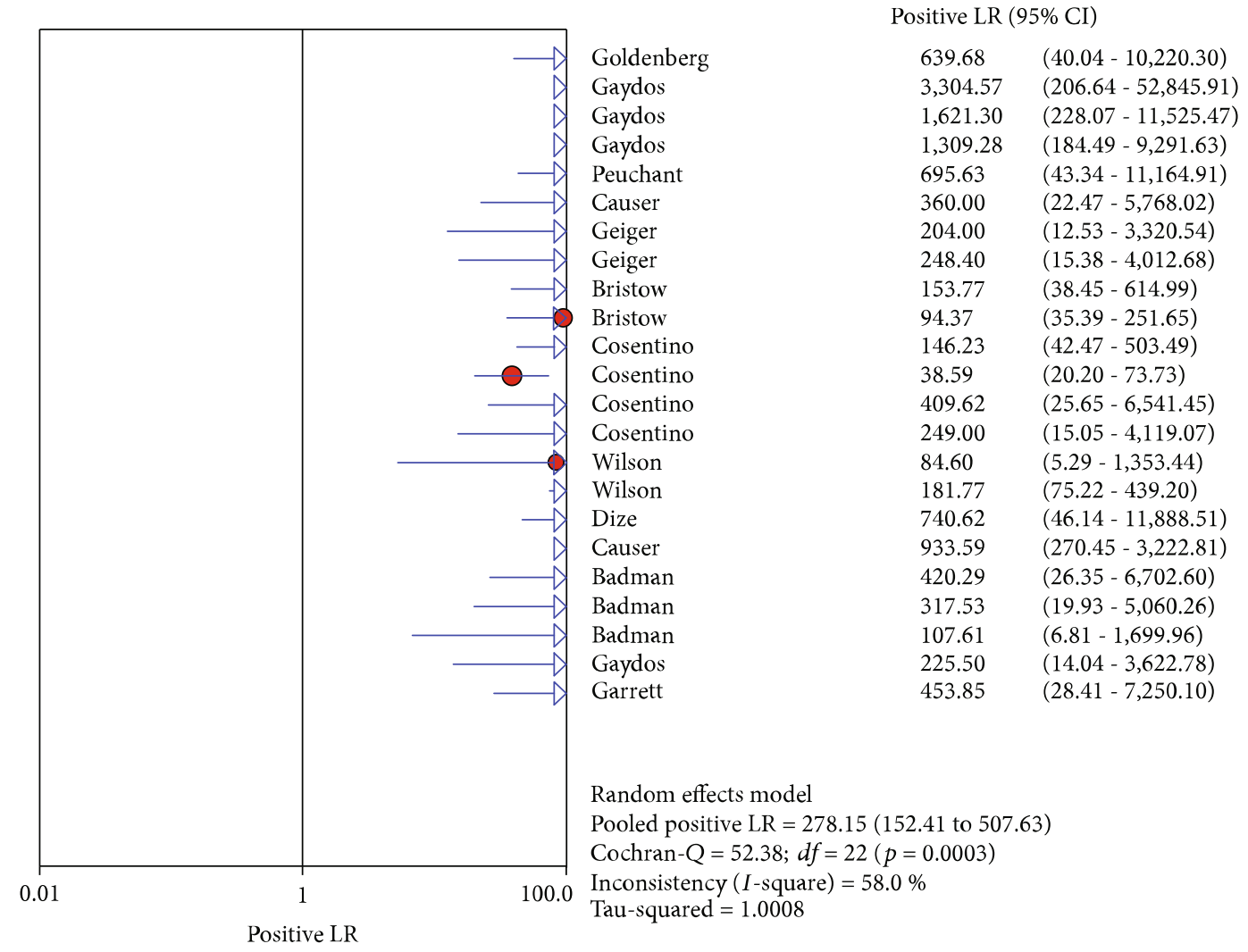

FIGURE 8: Forest plots of the combined positive LR of Xpert CT/NG for the diagnosis of Neisseria gonorrhoeae.

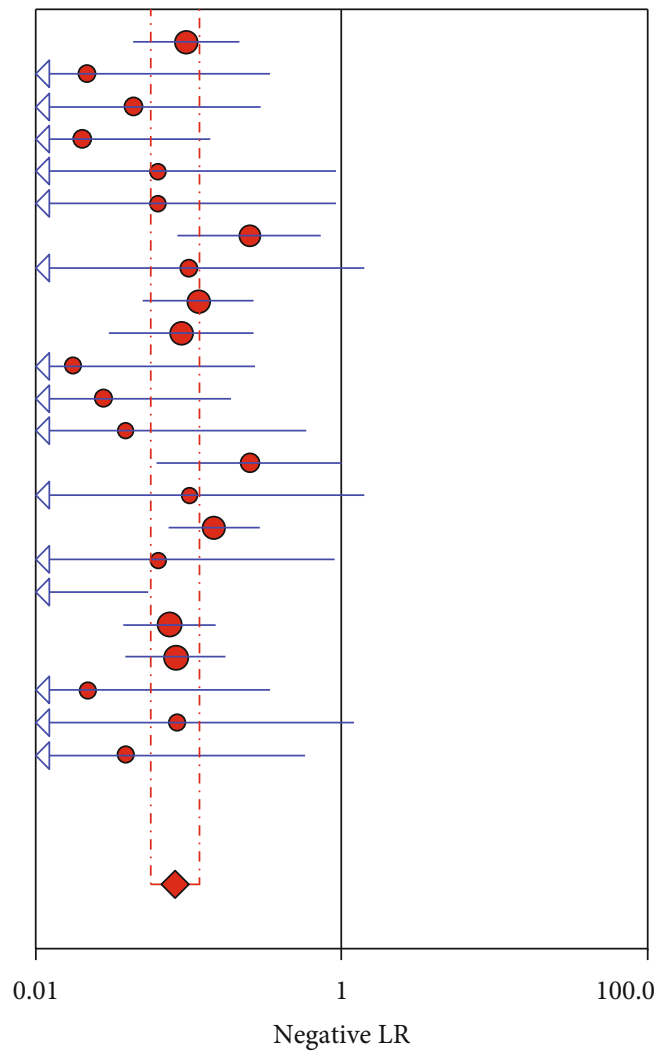

$\begin{array}{lll}\text { Goldenberg } & 0.10 & (0.04-0.21) \\ \text { Gaydos } & 0.02 & (0.00-0.34) \\ \text { Gaydos } & 0.04 & (0.01-0.30) \\ \text { Gaydos } & 0.02 & (0.00-0.14) \\ \text { Peuchant } & 0.06 & (0.00-0.92) \\ \text { Causer } & 0.06 & (0.00-0.92) \\ \text { Geiger } & 0.25 & (0.09-0.73) \\ \text { Geiger } & 0.10 & (0.01-1.39) \\ \text { Bristow } & 0.12 & (0.05-0.27) \\ \text { Bristow } & 0.09 & (0.03-0.26) \\ \text { Cosentino } & 0.02 & (0.00-0.27) \\ \text { Cosentino } & 0.03 & (0.00-0.19) \\ \text { Cosentino } & 0.04 & (0.00-0.58) \\ \text { Cosentino } & 0.25 & (0.06-1.00) \\ \text { Wilson } & 0.10 & (0.01-1.40) \\ \text { Wilson } & 0.15 & (0.07-0.29) \\ \text { Dize } & 0.06 & (0.00-0.92) \\ \text { Causer } & 0.00 & (0.00-0.05) \\ \text { Badman } & 0.07 & (0.04-0.15) \\ \text { Badman } & 0.08 & (0.04-0.17) \\ \text { Badman } & 0.02 & (0.00-0.34) \\ \text { Gaydos } & 0.08 & (0.01-1.19) \\ \text { Garrett } & 0.04 & (0.00-0.58)\end{array}$

Random effects model

Pooled negative $\mathrm{LR}=0.08(0.06$ to 0.12$)$

Cochran $-Q=31.15 ; d f=22(p=0.0930)$

Inconsistency $(I$-square $)=29.4 \%$

Negative LR

FIGURE 9: Forest plots of the combined negative LR of Xpert CT/NG for the diagnosis of Neisseria gonorrhoeae. 


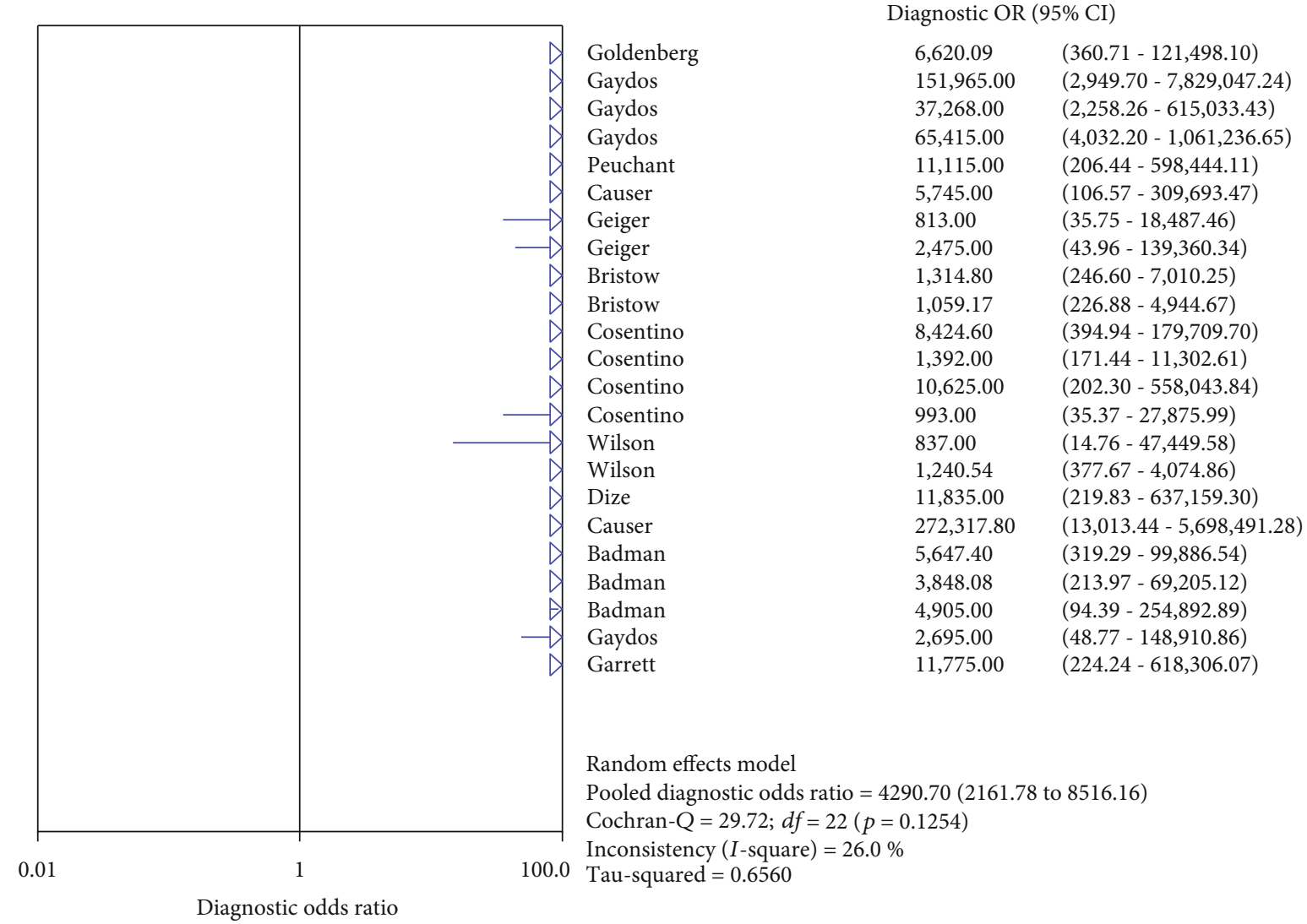

FIgURE 10: Forest plots of the combined diagnostic OR of Xpert CT/NG for the diagnosis of Neisseria gonorrhoeae.

In the subgroup analysis of specimen type in NG, the pooled sensitivity of anorectal, urine, and vaginal specimens was 0.93 (95\% CI: $0.90-0.96 ; I^{2}$ : $\left.32.6 \%\right), 0.94$ (95\% CI: $\left.0.88-0.97 ; I^{2}: 46.9 \%\right)$, and 0.96 (95\% CI: 0.79-1.00; $I^{2}$ : $39.6 \%)$, respectively. The pooled specificity of anorectal, urine, and vaginal specimens was 1.00 (95\% CI: 1.00-1.00; I ' $16.9 \%$ ), 1.00 (95\% CI: $1.00-1.00 ; I^{2}: 35.9 \%$ ), and 1.00 (95\% CI: $1.00-1.00 ; I^{2}: 0.0 \%$ ), respectively (Table 4 ).

In the subgroup analysis of gender in CT, the pooled sensitivity of female and male individuals was 0.91 (95\% CI: $0.87-0.93 ; I^{2}: 87.4 \%$ ) and 0.93 (95\% CI: $0.87-0.97 ; I^{2}$ : $52.6 \%)$, respectively. The pooled specificity of female and male individuals was 1.00 (95\% CI: 0.99-1.00; $\left.I^{2}: 67.5 \%\right)$ and 1.00 (95\% CI: $1.00-1.00 ; I^{2}: 28.1 \%$ ), respectively.

In the subgroup analysis of gender in NG, the pooled sensitivity of female and male individuals was 0.93 (95\% CI: $0.86-0.97 ; I^{2}: 46.1 \%$ ) and 0.96 (95\% CI: 0.89-0.99; $I^{2}$ : $35.2 \%)$, respectively. The pooled specificity of female and male individuals was 1.00 (95\% CI: $\left.1.00-1.00 ; I^{2}: 54.0 \%\right)$ and 1.00 (95\% CI: $1.00-1.00 ; I^{2}: 0.0 \%$ ), respectively (Table 5).

3.7. Publication Bias. The potential publication bias of these eight studies was evaluated using Deek's funnel plot asymmetry test. No publication bias was found in Deek's funnel plot of CT (Figure 13). The Egger test indicated that the publication bias of these studies in CT was low $(p=0.122)$. No publication bias was found in Deek's funnel plot of NG
(Figure 14). The Egger test indicated that the publication bias of these studies in NG was low $(p=0.048)$.

\section{Discussion}

CT and NG infections have become a major threat to human health [3]. In this context, the diagnostic efficacy of Xpert CT/NG for CT and NG becomes particularly important. In this meta-analysis, eight studies were searched and screened. A scientific and systematic evaluation of the diagnostic efficacy of Xpert CT/NG was conducted by analyzing the data extracted from the eight studies.

In this study, the results of systematic evaluation revealed the following: (1) In CT, the sensitivity, specificity, positive likelihood ratio (PLR); negative likelihood ratio (NLR); and DOR of Xpert CT/NG were 0.94, 0.99, 97.17, 0.07, and 1857.25, respectively. (2) In NG, the sensitivity, specificity, PLR, NLR, and DOR of Xpert CT/NG were 0.95, 1.00, $278.15,0.08$, and 4290.70, respectively. The positive LRs of CT and NG were both much larger than 10, and the negative LRs were both less than 0.1. The SROC AUC of CT and NG was 0.9956 and 0.9980 , respectively; both of which were very close to 1 . Besides, the SROC curves of both were very close to the upper left corner. Thus, it indicated that the diagnostic accuracy of Xpert CT/NG for CT and NG was very high. According to the results of the funnel plots of CT and NG, despite some asymmetric phenomena in the graphs of both 


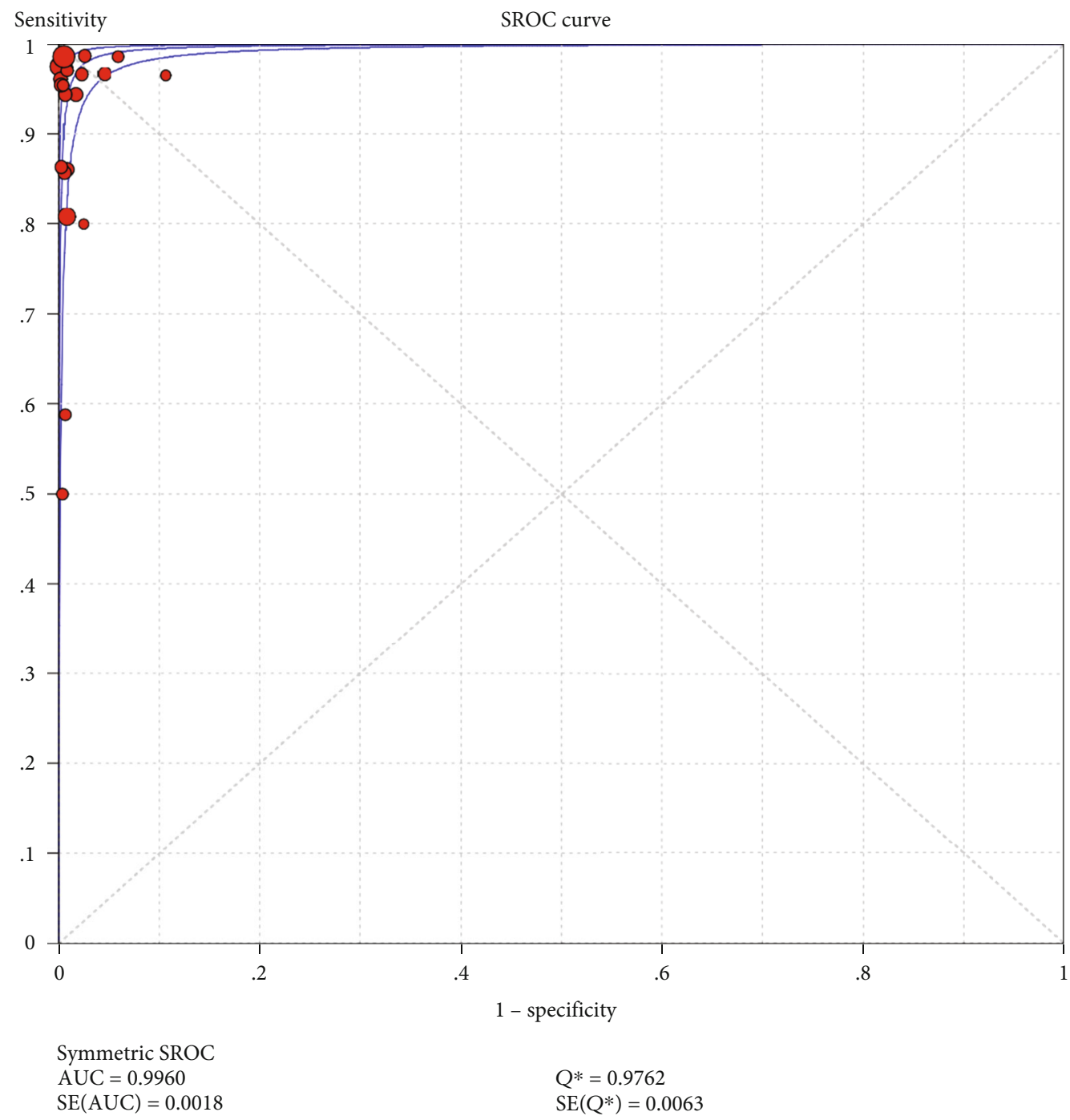

FIGURE 11: The summary receiver operating characteristic (SROC) curve of Xpert CT/NG in Chlamydia trachomatis.

due to the limited number of studies, the $p$ values $(0.122$ and 0.048 ) were greater than 0.01 , with no statistical significance, indicating that the possibility of publication bias was low.

Due to the obvious heterogeneity in this study, the subgroup analysis of CT and NG was conducted based on the sample type and gender to facilitate further description of the results. The results of CT analysis in sample type showed that $I^{2}$ values were more than $50 \%$ except for the combined sensitivity in "anorectal," which was $47.1 \%$, indicating high heterogeneity. In terms of gender, $I^{2}$ values were higher than $50 \%$ for both "male" and "female," but they were obviously higher for "female" than for "male." Therefore, heterogeneity existed in both "male" and "female," and "female" was higher in comparison. Meanwhile, the result of $\mathrm{NG}$ analysis in sample type showed that $I^{2}$ values were lower than $50 \%$, indicating low heterogeneity. In terms of gender, $I^{2}$ values of specificity in "female" were slightly higher than 50\%, while $I^{2}$ values of "male" were lower than $50 \%$, indicating low heterogeneity in "female," but not in "male." After in-depth study of these fourteen studies, it was believed that the rea- sons for the heterogeneity might be the following: (1) the specimens collected were either degraded or poorly mixed in the study [24], (2) the improper behavior of the patients when collecting the sample resulted in the incomplete specimens [28], and (3) before collecting vaginal specimens, female patients underwent vaginal cleansing [25]. The sensitivity and specificity of CT and NG in sample type were both greater than 0.9 , and the specificity of NG was 1 . In terms of sex, the combined sensitivity of CT and NG was greater than 0.9 , and the specificity was 1 . These results, on the one hand, indicated that Xpert CT/NG had a high accuracy in identifying anorectal, urethral, and vaginal specimens. On the other hand, no obvious sex-related difference existed in the identification accuracy of Xpert CT/NG for CT and NG. In addition, the data of "endocervical," "ocular," and "pharyngeal" were also extracted, but the subgroup analysis could not be conducted because of insufficient data. After the direct analysis of the data, it was not difficult to find that Xpert CT/NG also had high sensitivity and specificity in the identification of endocervical, ocular, and pharyngeal samples. 


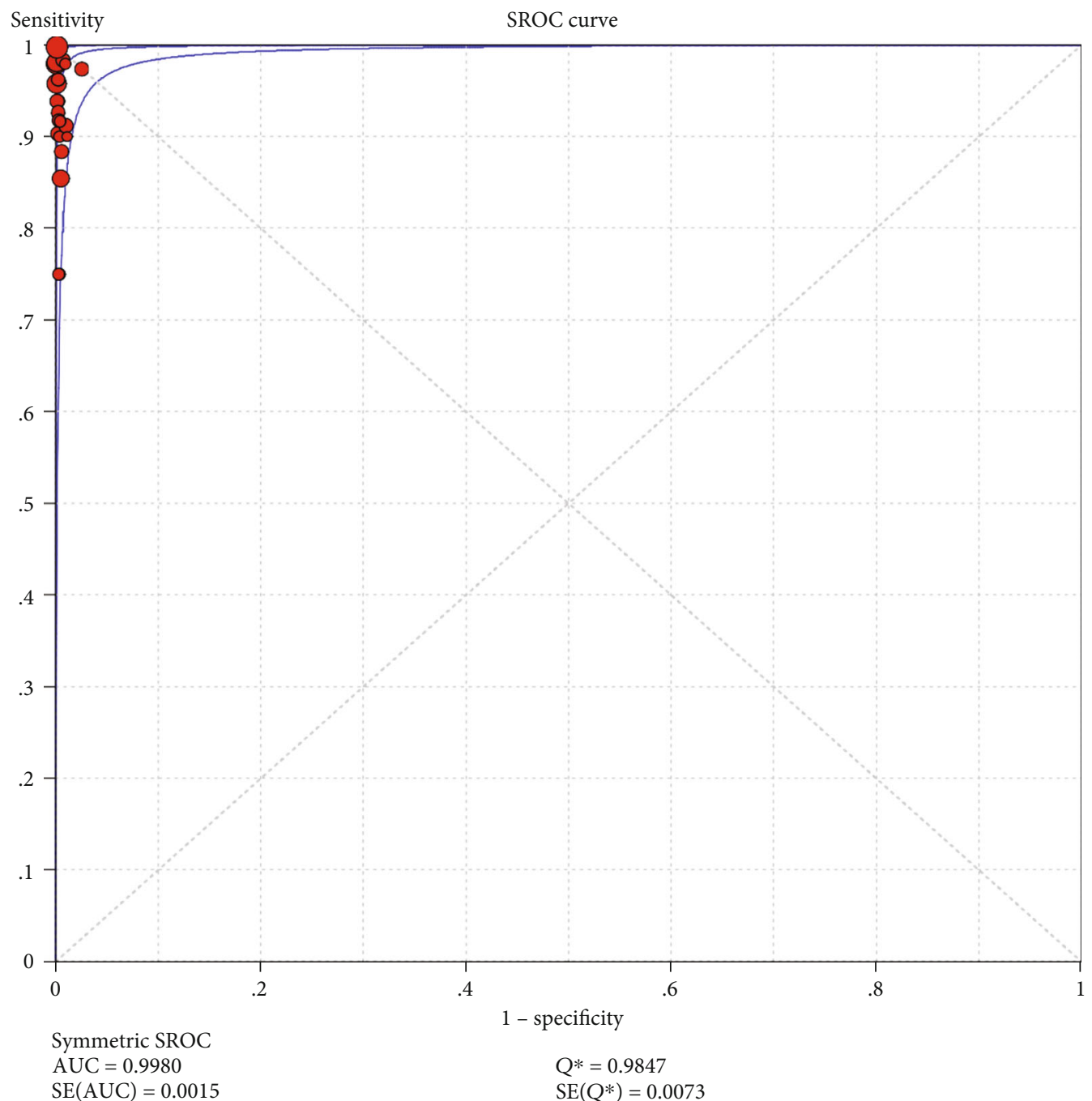

FIGURE 12: The summary receiver operating characteristic (SROC) curve of Xpert CT/NG in Neisseria gonorrhoeae.

TABLE 4: Subgroup analyses of Xpert CT/NG for the diagnosis of CT and NG infections in anorectal, urine, and vaginal specimens.

\begin{tabular}{|c|c|c|c|c|c|c|}
\hline Bacterial species & Type of specimens & Parameter & Estimates & $95 \% \mathrm{CI}$ & $p$ value & $I^{2}$ \\
\hline \multirow{6}{*}{ CT } & \multirow{2}{*}{ Anorectal } & Sensitivity & 0.94 & $0.91-0.96$ & 0.0664 & $47.1 \%$ \\
\hline & & Specificity & 0.99 & 0.98-0.99 & 0.0000 & $78.6 \%$ \\
\hline & \multirow{2}{*}{ Urine } & Sensitivity & 0.90 & $0.87-0.93$ & 0.0000 & $82.2 \%$ \\
\hline & & Specificity & 1.00 & $0.99-1.00$ & 0.0166 & $63.9 \%$ \\
\hline & \multirow{2}{*}{ Vaginal } & Sensitivity & 0.91 & 0.84-0.96 & 0.0000 & $90.9 \%$ \\
\hline & & Specificity & 0.99 & $0.98-1.00$ & 0.0075 & $79.6 \%$ \\
\hline \multirow{6}{*}{ NG } & \multirow{2}{*}{ Anorectal } & Sensitivity & 0.93 & $0.90-0.96$ & 0.1680 & $32.6 \%$ \\
\hline & & Specificity & 1.00 & $1.00-1.00$ & 0.2970 & $16.9 \%$ \\
\hline & \multirow{2}{*}{ Urine } & Sensitivity & 0.94 & $0.88-0.97$ & 0.0934 & $46.9 \%$ \\
\hline & & Specificity & 1.00 & $1.00-1.00$ & 0.1647 & $35.9 \%$ \\
\hline & \multirow{2}{*}{ Vaginal } & Sensitivity & 0.96 & $0.79-1.00$ & 0.1911 & $39.6 \%$ \\
\hline & & Specificity & 1.00 & $1.00-1.00$ & 1.0000 & $0.0 \%$ \\
\hline
\end{tabular}

Most of the NAATs use the fluorescence probe technology to detect amplified products in real time based on PCR. Compared with culture, conventional NAATs do not rely on live bacteria when detecting CT and NG and therefore are very beneficial for sample transportation [14]. With the same sensitivity and specificity as culture, the conventional 
TABle 5: Subgroup analyses of Xpert CT/NG for the diagnosis of CT and NG infections in gender.

\begin{tabular}{lclcccc}
\hline Bacterial species & Gender & Parameter & Estimates & $95 \%$ CI & $p$ value & $I^{2}$ \\
\hline \multirow{3}{*}{ CT } & \multirow{2}{*}{ Female } & Sensitivity & 0.91 & $0.87-0.93$ & 0.0000 & $87.4 \%$ \\
& & Specificity & 1.00 & $0.99-1.00$ & 0.0051 & $67.5 \%$ \\
& Male & Sensitivity & 0.93 & $0.87-0.97$ & 0.0770 & $52.6 \%$ \\
& & Specificity & 1.00 & $1.00-1.00$ & 0.2343 & $28.1 \%$ \\
NG & Female & Sensitivity & 0.93 & $0.86-0.97$ & 0.0844 & $46.1 \%$ \\
& & Specificity & 1.00 & $1.00-1.00$ & 0.0425 & $54.0 \%$ \\
& Male & Sensitivity & 0.96 & $0.89-0.99$ & 0.1867 & $35.2 \%$ \\
& & Specificity & 1.00 & $1.00-1.00$ & 0.9552 \\
\hline
\end{tabular}

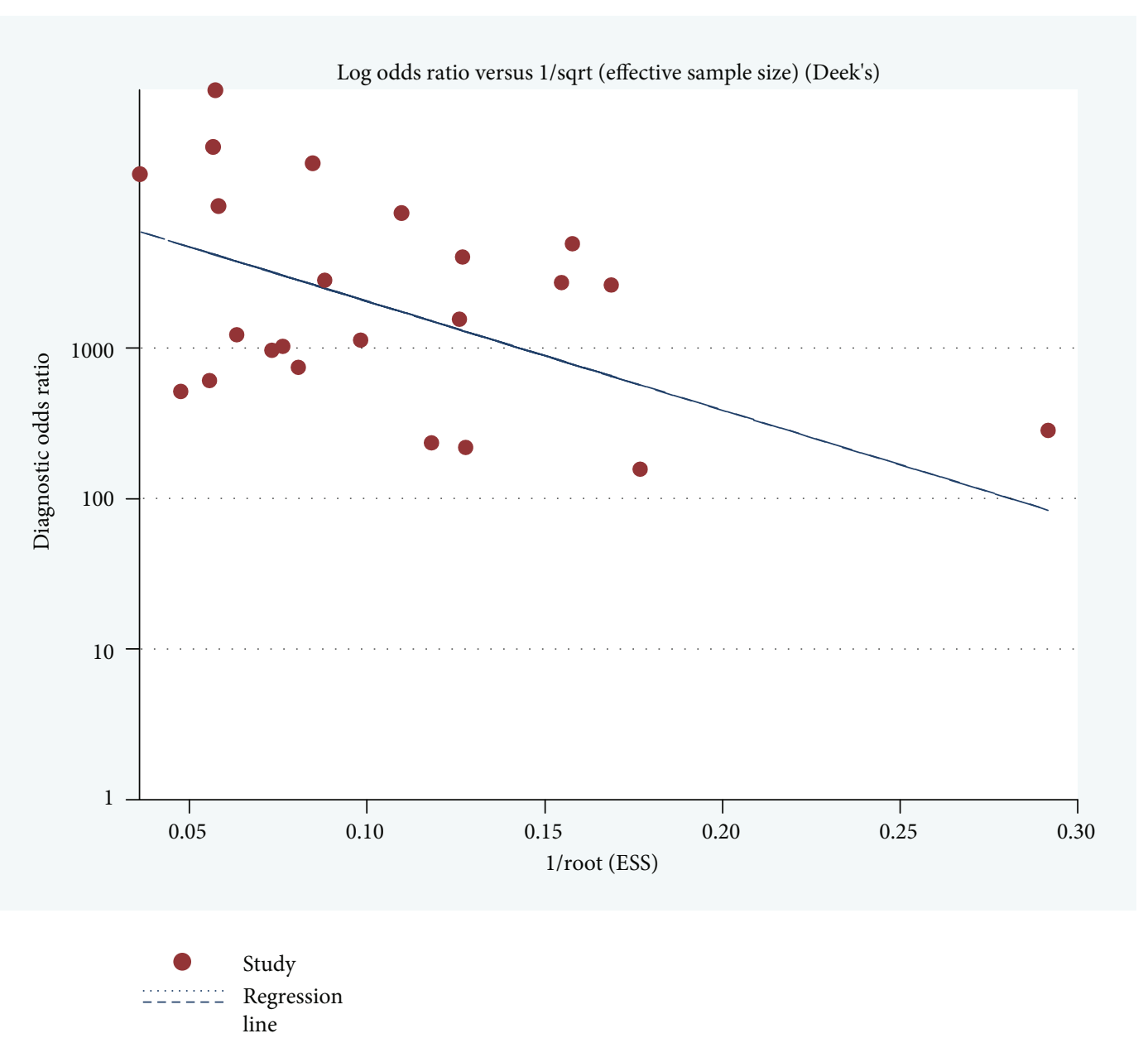

FIGURE 13: Deek's funnel plot asymmetry test to assess publication bias for Xpert CT/NG detection of Chlamydia trachomatis.

NAATs have replaced culture as the gold standard [36]. In 2002, the Centers for Disease Control and Prevention (CDC) recommended that NAAT-positive results should be confirmed with a second test to prevent unnecessary treatment and psychological testing. However, subsequent studies showed that unconfirmed positive results were not necessarily false positive, but may also be false negative, indirectly leading to the uncertainty of NAAT test results [37]. Sometimes, when the concentrations of some samples were too low, the NAAT detection rate was also very low [38]. In addition, some variants such as the Swedish variant (C. trachomatis strain E/SW2) could not be detected due to the defect in the target area of some conventional NAATs [39]. In this case, Xpert $\mathrm{CT} / \mathrm{NG}$, as an emerging NAAT, has advantages such as unique integration, allowing the simultaneous detection of multiple samples without interference [18]. Compared with the conventional NAATs, Xpert CT/NG has eliminated the existing shortcomings and improved the detection accuracy of CT and NG. The most striking thing is that the speed of detecting CT and NG has greatly increased [1], facilitating 


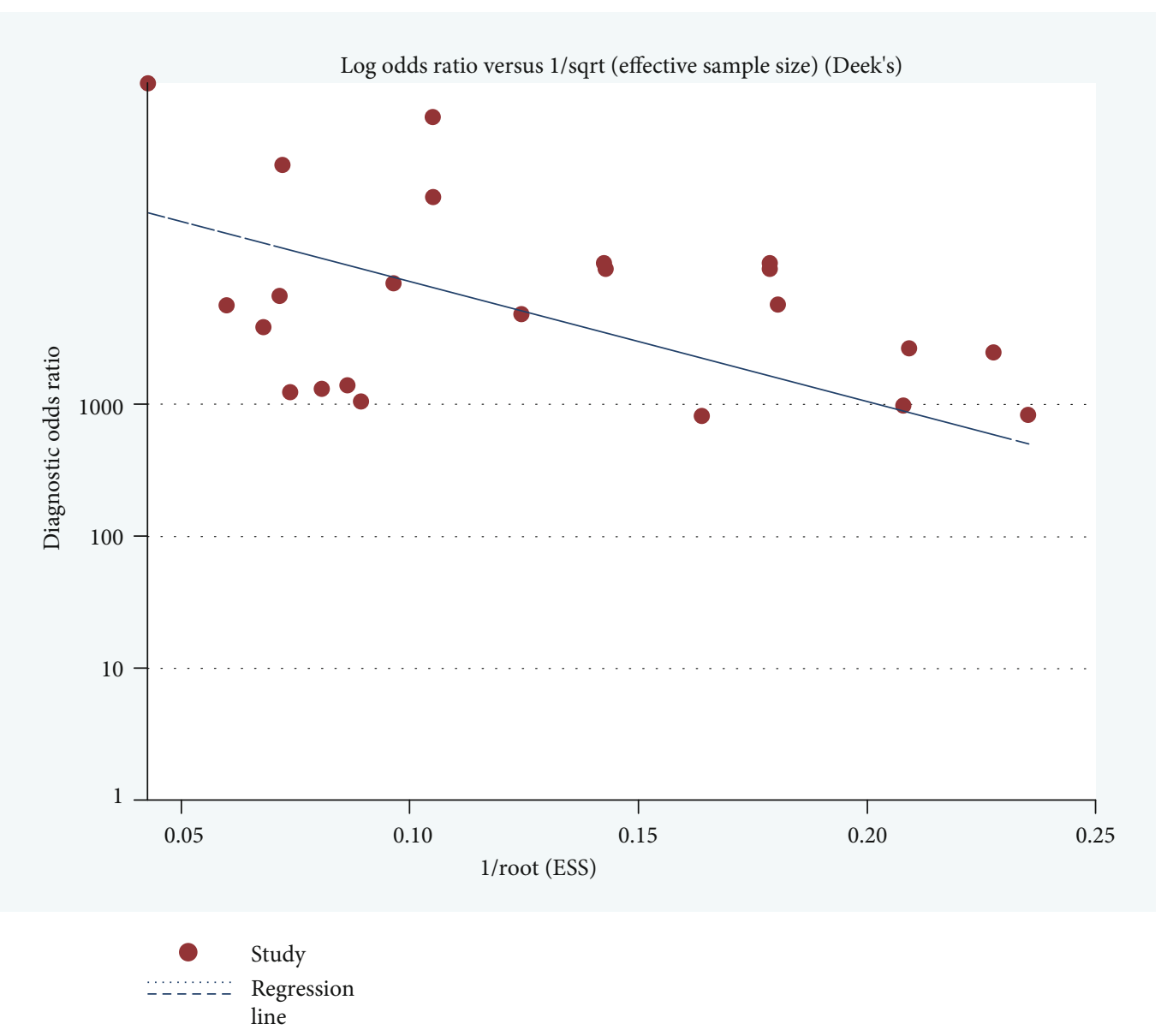

FIgURE 14: Deek's funnel plot asymmetry test to assess publication bias for Xpert CT/NG detection of Neisseria gonorrhoeae.

the timely treatment of patients. Therefore, Xpert CT/NG might become the preferred method for detecting CT and NG in the future.

In addition, Bristow et al. [40] published a new metaanalysis similar to our study in 2019. We carefully read and studied this article, and compared our study with it, and found several differences: (1) Compared with the Bristow's study, we searched the PubMed database, as well as the Embase, Cochrane Library, and Web of Science databases, broadening the data source. (2) In their study, only nongenital tract samples of the rectum and pharynx were included. On this basis, we also included ocular samples and genital tract samples like urine and vagina. In addition to analyzing all the data, we also performed a subgroup analysis based on sample type and gender. (3) On the basis of the five literatures included in their study, a total of 14 literatures were included by us. In addition, we found that the heterogeneity of the final results of their study is relatively low compared with ours, but we believe that this is caused by the large and extensive data volume. Therefore, we believe that our study can provide more information for clinical reference.

This study had some limitations. First, despite including all eligible studies in strict accordance with the criteria, it was difficult to ensure that no article was missing. Sec- ond, high heterogeneity was found in the analysis of the results, reducing the reliability of the results of this study. Third, only studies in English were searched and included, leading to bias.

\section{Conclusions}

In summary, this meta-analysis showed that Xpert CT/NG had high diagnostic accuracy for CT and NG. Further, Xpert CT/NG had high sensitivity and specificity in the detection of anorectal, urethral, and vaginal samples, with no obvious sexrelated difference. Therefore, Xpert CT/NG might become the primary method for detecting CT and NG and even the gold standard for diagnosis in the future. However, the findings need further validation.

$\begin{array}{ll}\text { Abbreviations } \\ \text { CT: } & \text { Chlamydia trachomatis } \\ \text { NG: } & \text { Neisseria gonorrhoeae } \\ \text { QUADAS: } & \text { Quality assessment of diagnostic accuracy } \\ & \text { studies } \\ \text { SEN: } & \text { Sensitivity } \\ \text { SPE: } & \text { Specificity } \\ \text { PLR: } & \text { Positive likelihood ratio }\end{array}$




$\begin{array}{ll}\text { NLR: } & \text { Negative likelihood ratio } \\ \text { DOR: } & \text { Diagnostic odds ratio } \\ \text { AUC: } & \text { The area under the curve } \\ \text { SROC: } & \text { The summary receiver operating characteristic } \\ \text { CI: } & \text { Confidence interval } \\ \text { STIs: } & \text { Sexually transmitted infections } \\ \text { RBs: } & \text { Reticulate bodies } \\ \text { NAATs: } & \text { Nucleic acid amplification tests } \\ \text { FQ-PCR: } & \text { Fluorescent quantitative polymerase chain } \\ & \text { reaction } \\ \text { CDC: } & \text { The Centers for Disease Control and Prevention } \\ \text { PCR: } & \text { Polymerase chain reaction } \\ \text { TP: } & \text { True positive } \\ \text { FP: } & \text { False positive } \\ \text { TN: } & \text { True negative } \\ \text { FN: } & \text { False negative } \\ \text { Y: } & \text { Yes } \\ \text { UC: } & \text { Unclear } \\ \text { N: } & \text { No } \\ I^{2}: & \text { Inconsistency (I-square). }\end{array}$

\section{Data Availability}

The original data included in our study were from 14 original research articles; all of which can be searched on PubMed database (https://www.ncbi.nlm.nih.gov/pubmed/).

\section{Conflicts of Interest}

The authors declare that they have no competing interests.

\section{Authors' Contributions}

ZX Li, S Ouyang, GD Zhu, TX Ji, Y Xia, and XG Guo conceived and designed the experiments. TA Xie, YL Liu, RC Meng, and XS Liu analyzed the studies and extracted the data. TA Xie, YL Liu, SJ Fan, KY Fang, ZJ He, and CM Chen contributed to making tables. TA Xie, YL Liu, ST Deng, QR Lin, and ZY Pan contributed to the production of figures. All authors participated in the writing, reading, and revising of the manuscript and approved the final version of the manuscript. Tian-Ao Xie and Ye-Ling Liu contributed equally to this work.

\section{Acknowledgments}

We sincerely thank all those who participated in this study. Thank them for their excellent work and valuable participation. This study was supported by the Guangzhou Medical University (No. 2019A020), the Third Clinical School of Guangzhou Medical University (No. 2018B088), the grants from the Natural Science Foundation of Guangdong Province (No. 2015A030313684), and the National Nature Science Foundation of China (No. 81700004 and No. 81803884).

\section{Supplementary Materials}

Supplementary Figure 1: PRISM flow chart for article search to the system. (Supplementary Materials)

\section{References}

[1] N. Bourgeois-Nicolaos, F. Jaureguy, S. Pozzi-Gaudin et al., "Benefits of rapid molecular diagnosis of Chlamydia trachomatis and Neisseria gonorrhoeae infections in women attending family planning clinics," Sexually Transmitted Diseases, vol. 42, no. 11, pp. 652-653, 2015.

[2] S. F. Situ, C. H. Ding, S. Nawi, A. Johar, and R. Ramli, "Conventional versus molecular detection of Chlamydia trachomatis and Neisseria gonorrhoeae among males in a sexually transmitted infections clinic," The Malaysian Journal of Pathology, vol. 39, no. 1, pp. 25-31, 2017.

[3] W. P. Loomis and M. N. Starnbach, "T cell responses to Chlamydia trachomatis," Current Opinion in Microbiology, vol. 5, no. 1, pp. 87-91, 2002.

[4] K. Manavi, "A review on infection with Chlamydia trachomatis," Best Practice \& Research Clinical Obstetrics \& Gynaecology, vol. 20, no. 6, pp. 941-951, 2006.

[5] C. Foschi, L. Laghi, A. D'Antuono et al., "Urine metabolome in women with Chlamydia trachomatis infection," PLoS One, vol. 13, no. 3, article e0194827, 2018.

[6] K. R. Salow, A. C. Cohen, C. C. Bristow, M. R. McGrath, and J. D. Klausner, "Comparing mail-in self-collected specimens sent via United States Postal Service versus clinic-collected specimens for the detection of Chlamydia trachomatis and Neisseria gonorrhoeae in extra-genital sites," PLoS One, vol. 12, no. 12, article e0189515, 2017.

[7] C. C. Su, J. R. Bolla, N. Kumar et al., "Structure and function of Neisseria gonorrhoeae MtrF illuminates a class of antimetabolite efflux pumps," Cell Reports, vol. 11, no. 1, pp. 61-70, 2015.

[8] J. Rowley, S. Vander Hoorn, E. Korenromp et al., Global and regional estimates of the prevalence and incidence of four curable sexually transmitted infections in 2016, WHO Bulletin, 2019, https://www.who.int/bulletin/online_first/BLT.18 .228486.pdf.

[9] Report on global sexually transmitted infection surveillance, World Health Organization, Geneva, 2018, Licence: CC BYNC-SA 3.0 IGO], https://www.who.int/reproductivehealth/ publications/stis-surveillance-2018/en/.

[10] M. C. Ortiz, C. Lefimil, P. I. Rodas et al., "Neisseria gonorrhoeae modulates immunity by polarizing human macrophages to a M2 profile," PLoS One, vol. 10, no. 6, article e0130713, 2015.

[11] I. Bozicevic, K. A. Fenton, I. M. C. Martin et al., "Epidemiological correlates of asymptomatic gonorrhea," Sexually Transmitted Diseases, vol. 33, no. 5, pp. 289-295, 2006.

[12] M. Unemo, D. Golparian, L. Sánchez-Busó et al., “The novel 2016 WHO Neisseria gonorrhoeae reference strains for global quality assurance of laboratory investigations: phenotypic, genetic and reference genome characterization," The Journal of Antimicrobial Chemotherapy, vol. 71, no. 11, pp. 30963108, 2016.

[13] J. K. Hansen, K. P. Demick, J. M. Mansfield, and K. T. Forest, "Conserved regions from Neisseria gonorrhoeae pilin are immunosilent and not immunosuppressive," Infection and Immunity, vol. 75, no. 8, pp. 4138-4147, 2007.

[14] T. Meyer, "Diagnostic procedures to detect Chlamydia trachomatis infections," Microorganisms, vol. 4, no. 3, p. 25, 2016.

[15] A. Seidler, M. Thinschmidt, S. Deckert et al., "The role of psychosocial working conditions on burnout and its core component emotional exhaustion - a systematic review," 
Journal of Occupational Medicine and Toxicology, vol. 9, no. 1, p. 10, 2014.

[16] C. A. Gaydos, "Review of use of a new rapid real-time PCR, the Cepheid GeneXpert ${ }^{\circledR}$ (Xpert) CT/NG assay, for Chlamydia trachomatis and Neisseria gonorrhoeae: results for patients while in a clinical setting," Expert Review of Molecular Diagnostics, vol. 14, no. 2, pp. 135-137, 2014.

[17] S. Raja, J. Ching, L. Xi et al., "Technology for automated, rapid, and quantitative PCR or reverse transcription-PCR clinical testing," Clinical Chemistry, vol. 51, no. 5, pp. 882-890, 2005.

[18] M. Drancourt, A. Michel-Lepage, S. Boyer, and D. Raoult, "The point-of-care laboratory in clinical microbiology," Clinical Microbiology Reviews, vol. 29, no. 3, pp. 429-447, 2016.

[19] C. Gaydos and J. Hardick, "Point of care diagnostics for sexually transmitted infections: perspectives and advances," Expert Review of Anti-Infective Therapy, vol. 12, no. 6, pp. 657-672, 2014.

[20] P. F. Whiting, A. W. Rutjes, M. E. Westwood et al., "QUADAS-2: a revised tool for the quality assessment of diagnostic accuracy studies," Annals of Internal Medicine, vol. 155, no. 8, pp. 529-536, 2011.

[21] J. Zamora, V. Abraira, A. Muriel, K. Khan, and A. Coomarasamy, "Meta-DiSc: a software for meta-analysis of test accuracy data," BMC Medical Research Methodology, vol. 6, no. 1, 2006.

[22] C. A. Gaydos, B. van der Pol, M. Jett-Goheen et al., "Performance of the Cepheid CT/NG Xpert rapid PCR test for detection of Chlamydia trachomatis and Neisseria gonorrhoeae," Journal of Clinical Microbiology, vol. 51, no. 6, pp. 16661672, 2013.

[23] O. Peuchant, S. de Diego, C. le Roy et al., "Comparison of three real-time PCR assays for the detection of Chlamydia trachomatis and Neisseria gonorrhoeae in young pregnant women," Diagnostic Microbiology and Infectious Disease, vol. 83, no. 4, pp. 335-337, 2015.

[24] C. C. Bristow, M. R. McGrath, A. C. Cohen, L. J. Anderson, K. K. Gordon, and J. D. Klausner, "Comparative evaluation of 2 nucleic acid amplification tests for the detection of Chlamydia trachomatis and Neisseria gonorrhoeae at extragenital sites," Sexually Transmitted Diseases, vol. 44, no. 7, pp. 398400, 2017.

[25] L. A. Cosentino, C. S. Danby, L. K. Rabe et al., "Use of nucleic acid amplification testing for diagnosis of extragenital sexually transmitted infections," Journal of Clinical Microbiology, vol. 55, no. 9, pp. 2801-2807, 2017.

[26] S. P. Wilson, T. Vohra, J. Goldberg et al., "Reliable rapid assay for gonorrhea and chlamydia in the emergency department," The Journal of Emergency Medicine, vol. 53, no. 6, pp. 890895, 2017.

[27] L. M. Causer, R. J. Guy, S. N. Tabrizi et al., "Molecular test for chlamydia and gonorrhoea used at point of care in remote primary healthcare settings: a diagnostic test evaluation," Sexually Transmitted Infections, vol. 94, no. 5, pp. 340-345, 2018.

[28] S. G. Badman, B. Willie, R. Narokobi et al., "A diagnostic evaluation of a molecular assay used for testing and treating anorectal chlamydia and gonorrhoea infections at the pointof-care in Papua New Guinea," Clinical Microbiology and Infection, vol. 25, no. 5, pp. 623-627, 2019.

[29] N. Garrett, N. Mitchev, F. Osman et al., "Diagnostic accuracy of the Xpert CT/NG and OSOM Trichomonas rapid assays for point-of-care STI testing among young women in South
Africa: a cross-sectional study," BMJ Open, vol. 9, no. 2, article e026888, 2019.

[30] L. M. Causer, B. Hengel, L. Natoli et al., "A field evaluation of a new molecular-based point-of-care test for chlamydia and gonorrhoea in remote Aboriginal health services in Australia," Sexual Health, vol. 12, no. 1, pp. 27-33, 2015.

[31] S. D. Goldenberg, J. Finn, E. Sedudzi, J. A. White, and C. Y. Tong, "Performance of the GeneXpert CT/NG assay compared to that of the Aptima AC2 assay for detection of rectal Chlamydia trachomatis and Neisseria gonorrhoeae by use of residual Aptima samples," Journal of Clinical Microbiology, vol. 50, no. 12, pp. 3867-3869, 2012.

[32] L. Dize, B. Silver, and C. Gaydos, "Comparison of the Cepheid GeneXpert CT/NG assay to the Hologic Aptima Combo2 assay for the detection of Chlamydia trachomatis and Neisseria gonorrhoeae in self-collected rectal swabs," Diagnostic Microbiology and Infectious Disease, vol. 90, no. 2, pp. 83-84, 2018.

[33] R. Geiger, D. M. Smith, S. J. Little, and S. R. Mehta, "Validation of the GeneXpert ${ }^{\circledR} \mathrm{CT} / \mathrm{NG}$ assay for use with male pharyngeal and rectal swabs," Austin Journal of HIV/AIDS Research, vol. 3, p. 1021, 2016.

[34] C. A. Gaydos, M. C. Ako, M. Lewis, Y. H. Hsieh, R. E. Rothman, and A. F. Dugas, "Use of a rapid diagnostic for Chlamydia trachomatis and Neisseria gonorrhoeae for women in the emergency department can improve clinical management: report of a randomized clinical trial," Annals of Emergency Medicine, vol. 74, no. 1, pp. 36-44, 2019.

[35] A. Jenson, L. Dize, H. Mkocha et al., "Field evaluation of the Cepheid GeneXpert Chlamydia trachomatis assay for detection of infection in a trachoma endemic community in Tanzania," PLoS Neglected Tropical Diseases, vol. 7, no. 7, article e2265, 2013.

[36] L. H. Bachmann, R. E. Johnson, H. Cheng et al., "Nucleic acid amplification tests for diagnosis of Neisseria gonorrhoeae and Chlamydia trachomatis rectal infections," Journal of Clinical Microbiology, vol. 48, no. 5, pp. 1827-1832, 2010.

[37] J. Schachter, J. M. Chow, H. Howard, G. Bolan, and J. Moncada, "Detection of Chlamydia trachomatis by nucleic acid amplification testing: our evaluation suggests that CDCrecommended approaches for confirmatory testing are illadvised," Journal of Clinical Microbiology, vol. 44, no. 7, pp. 2512-2517, 2006.

[38] C. M. Black, E. M. Driebe, L. A. Howard et al., "Multicenter study of nucleic acid amplification tests for detection of Chlamydia trachomatis and Neisseria gonorrhoeae in children being evaluated for sexual abuse," The Pediatric Infectious Disease Journal, vol. 28, no. 7, pp. 608-613, 2009.

[39] T. Ripa and P. A. Nilsson, "A Chlamydia trachomatis strain with a 377-bp deletion in the cryptic plasmid causing falsenegative nucleic acid amplification tests," Sexually Transmitted Diseases, vol. 34, no. 5, pp. 255-256, 2007.

[40] C. C. Bristow, S. R. Morris, S. J. Little, S. R. Mehta, and J. D. Klausner, "Meta-analysis of the Cepheid Xpert ${ }^{\circledR}$ CT/NG assay for extragenital detection of Chlamydia trachomatis (CT) and Neisseria gonorrhoeae (NG) infections," Sexual Health, vol. 16, no. 4, pp. 314-319, 2019. 